Provided for non-commercial research and education use. Not for reproduction, distribution or commercial use.

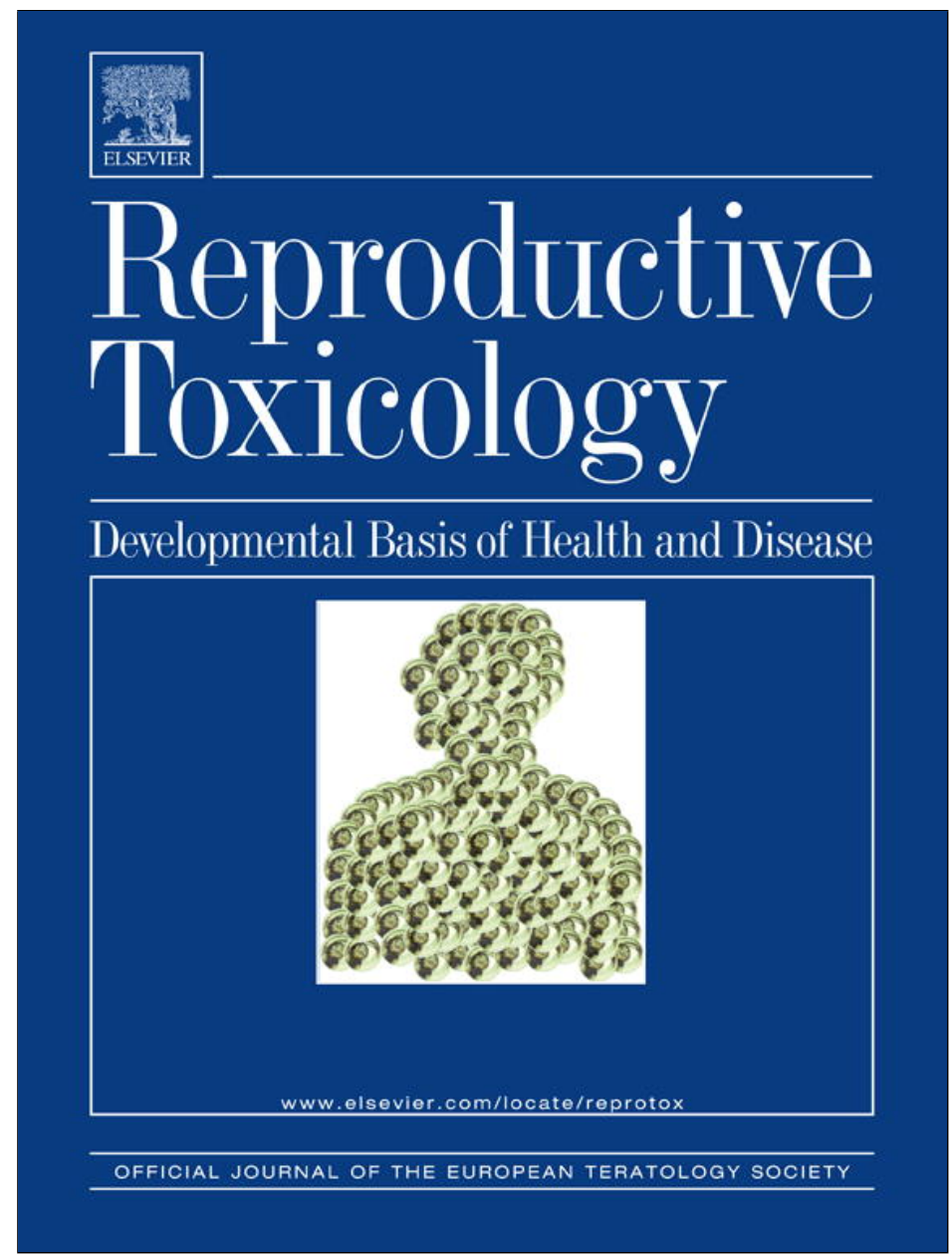

(This is a sample cover image for this issue. The actual cover is not yet available at this time.)

This article appeared in a journal published by Elsevier. The attached copy is furnished to the author for internal non-commercial research and education use, including for instruction at the authors institution and sharing with colleagues.

Other uses, including reproduction and distribution, or selling or licensing copies, or posting to personal, institutional or third party websites are prohibited.

In most cases authors are permitted to post their version of the article (e.g. in Word or Tex form) to their personal website or institutional repository. Authors requiring further information regarding Elsevier's archiving and manuscript policies are encouraged to visit:

http://www.elsevier.com/copyright 


\title{
A panel of biological tests reveals developmental effects of pharmaceutical pollutants on late stage zebrafish embryos
}

\author{
Benoist Pruvot, Yobhana Quiroz, Audrey Voncken, Nathalie Jeanray, Amandine Piot, \\ Joseph A. Martial, Marc Muller* \\ Laboratory for Molecular Biology and Genetic Engineering, Université de Liège, GIGA-R B34, Sart Tilman, 4000 Liège, Belgium
}

\section{A R T I C L E I N F O}

\section{Article history:}

Received 29 April 2011

Received in revised form 9 July 2012

Accepted 13 July 2012

Available online $\mathrm{xxx}$

\section{Keywords:}

Zebrafish

Toxicity

Teratogenicity

Psychotropic drugs

Valproic acid

Carbamazepine

$\mathrm{LiCl}$

Pentobarbital

Caffeine

Theophylline

\begin{abstract}
A B S T R A C T
Standard toxicological assays using the zebrafish model system evaluate lethality and teratogenicity upon exposure during the first 2 days after fertilization. We tested the biological effects of several widely used drugs on zebrafish by acute treatment for $24 \mathrm{~h}$ starting at late embryonic stages, between 48 and $72 \mathrm{~h}$ post-fertilization. For 4 out of 6 compounds, we observed a higher sensitivity of late stage zebrafish embryos for general toxicity (lethality) compared to younger embryos. Morphological defects such as edema, body curvature, delayed growth, decreased heart rate and locomotion were observed for each of the compounds tested, often at sublethal concentrations. Gene expression studies on a set of four selected genes revealed a specific regulatory pattern for the different compounds tested. Our results allow us to compare various toxicological endpoints and may contribute to the design of a rational high throughput approach using the zebrafish model.
\end{abstract}

() 2012 Elsevier Inc. All rights reserved.

\section{Introduction}

Due to their numerous biological and technological advantages (e.g. small size, ex vivo development and larvae transparency), zebrafish larvae allow observation of drug effects in vivo on a large number of individuals, as shown by several drug screening programs that have been performed using this model [1,2]. Studies include lethal, teratogenic, cardiological, neurological [3] or behavioral effects [4], while zebrafish models for diseases such as cancer [5-7] or Alzheimer [8,9] are used for pharmacological assays to test drug efficiency. Taken together, these considerations make zebrafish a very powerful toxicological model $[10,11]$.

Biological effect tests in zebrafish are usually performed by continuous exposure of the embryos to the test compound starting at the earliest possible stage, i.e. $2-3 \mathrm{~h}$ post-fertilization (hpf). Typical evaluated endpoints are the major developmental events, such as gastrulation, conversion-extension, epiboly, segmentation, tail detachment, otolith and eye formation, heart beat and blood circulation [12], all taking place during the first $48 \mathrm{~h}$ of development.

\footnotetext{
* Corresponding author. Tel.: +32 4366 4437; fax: +32 43664198.

E-mail address: m.muller@ulg.ac.be (M. Muller).
}

Recently, comparison of purely teratogenesis tests (concentrating on the effects during the first $48 \mathrm{~h}$ ) with tests in adults revealed that exposure should be extended beyond $48 \mathrm{hpf}$ for better consistency [13]. The third day of zebrafish development is critical for organogenesis in the developing larva; many regulatory pathways involved in early development still play a role during these later stages, while other potential drug targets might only be present in older larvae or adults. To evaluate specifically the importance of this late developmental period in teratogenesis, we decided to let the embryos develop normally until $48 \mathrm{hpf}$ and then to investigate the effects of various compounds by exposure between $48 \mathrm{hpf}$ and $72 \mathrm{hpf}$. Comparison of these results with those obtained upon exposure at earlier stages would allow to gain new insight into the timing of a particular effect during development and possibly also about the molecular mechanism of action. Near completion of the zebrafish genome allows genetic approaches to determine modulation of gene expression induced by drug exposure. One of our additional aims was to assess gene expression changes caused by drug treatment during the organogenesis period, between 2 and $3 \mathrm{dpf}$.

Pharmaceuticals recently attracted the attention of the scientific community as a new class of environmental contaminants. Extensively used in human and veterinary medicine, these compounds 
are excreted after application in their native or metabolized form and are increasingly found in aquatic systems [14-16] and even in (chlorinated) drinking water [17-19], thus triggering the concern about their pharmacological effects on the aquatic fauna. Among these molecules, neuroactive compounds appear as a major target for such evaluations, due to their increasing human consumption and consequently their presence in wastewater. We chose valproic acid (VPA), carbamazepine (CBZ) and lithium that are used for treatment of bipolar disorders, while VPA and CBZ also act on epilepsy $[20,21]$. Pentobarbital was chosen as a representative of barbiturates, largely known for their sedative, anxiolytic, anticonvulsive and hypnotic properties. Two anxiogenic drugs were also tested: caffeine and theophylline.

Here, we assessed various biological effects of psychotropic drugs on zebrafish larvae.

- We determined lethality at $72 \mathrm{hpf}$ after $24 \mathrm{~h}$ of exposure and compared these results to those obtained by exposure during the first 2 days of development,

- we investigated whether exposure between 48 and 72 hpf would lead to morphological defects,

- we determined cardiac or behavioral effects,

- and finally we analyzed modulation of gene expression at $72 \mathrm{hpf}$ after $24 \mathrm{~h}$ of exposure.

\section{Materials and methods}

\subsection{Substances}

Carbamazepine (CBZ), valproic acid (VPA), caffeine, theophylline, lithium chloride ( $\mathrm{LiCl}$ ) and pentobarbital were purchased from Sigma Aldrich (St. Louis, MO). Stock solutions were prepared by dissolving the pure chemicals in E3 medium (caffeine, theophylline, VPA, pentobarbital and $\mathrm{LiCl}$ ) or ethanol (CBZ) and then diluted to the desired concentrations in E3 medium. Final ethanol concentrations were $\leq 1 \%$ in the treatment solution. Effects of ethanol alone were evaluated at $1 \%$, the maximum concentration used during the assays.

\subsection{Zebrafish maintenance}

Adult zebrafish strain $\mathrm{AB}$ (ZIRC, Eugene, OR) was kept at $28^{\circ} \mathrm{C}$ as described [22]. The light:dark cycle was 14:10 h. Wild-type fish were mated and spawning was stimulated by the onset of light. Then, eggs were collected and placed at $28^{\circ} \mathrm{C}$ in Petri dishes containing $\mathrm{E} 3$ medium $\left(5 \mathrm{mmol} / \mathrm{L} \mathrm{NaCl}, 0.17 \mathrm{mmol} / \mathrm{L} \mathrm{KCl}, 0.4 \mathrm{mmol} / \mathrm{L} \mathrm{CaCl}_{2}\right.$, and $0.16 \mathrm{mmol} / \mathrm{L} \mathrm{MgSO}_{4}$ ). Embryos and larvae were staged according to Kimmel et al. [23]. The age of the embryos and larvae is indicated as hours post fertilization (hpf) or days post fertilization (dpf). Animal care and all experimentation were conducted in compliance with Belgian and European laws (Authorization: LA1610002 Ethical commission protocol ULg1076 and ULg624).

\subsection{Drug treatment and larvae observation}

Treatments were administered to $2 \mathrm{dpf}$ zebrafish larvae distributed in pools of 25 into 6-well plates in E3 medium. One day post treatment ( $3 \mathrm{dpf}$ ), the larvae were rinsed twice in $\mathrm{E} 3$ before observation. All experiments were carried out at least in triplicate on $n=25$ larvae per test, each experiment was performed at least three times. Survival and morphological/developmental defects were assessed on days 1 and 4 days post treatment ( 3 and $6 \mathrm{dpf}$ ) using an Olympus SZX10 stereomicroscope coupled with an Olympus XC50 camera. To assess teratogenicity, the surviving larvae were observed for morphological defects and the number of larvae presenting at least one morphological defect was reported as percentage of the surviving larvae. For LC50, LC10, EC50 and EC10 values, Graphpad software was used. The teratogenic index (TI), defined as the ratio between $\mathrm{LC}_{50}$ and $\mathrm{EC}_{50}$, was calculated; a substance is considered to be teratogenic when $\mathrm{TI}>1$, and considered as producing embryo lethal effects when $\mathrm{TI} \leq 1$. For early lethality determination, treatments were similarly performed starting at $4 \mathrm{hpf}$ and the survival rates were assessed at 24 and $48 \mathrm{hpf}$ after continuous treatment.

\subsection{Heart rate}

Heart beat rate was determined after 1 day treatment ( $3 \mathrm{dpf}$ ) by manual counting using an Olympus SZX10 stereomicroscope during $1 \mathrm{~min}$ on at least $n=10$ larvae per condition in triplicate. The results are presented as beats per min (bpm).

\subsection{Behavioral measurements}

The behavior of individual exposed and control larvae was analyzed 4 days after drug exposure ( $6 \mathrm{dpf}$ ) using the Zebrabox (Viewpoint, Lyon, France). For each larvae, activity (fraction of time spent in activity) and velocity (distance covered during active episodes) were determined according to the manufacturer's instructions by recording movement during $1 \mathrm{~min}$ time intervals, accumulated over $30 \mathrm{~min}$ on at least $n=10$ larvae in triplicate, the results are presented in percent for activity and $\mathrm{mm} / \mathrm{s}$ for velocity.

\subsection{Reverse transcription and real time polymerase chain reaction}

Total RNA from pools of 100 treated or control larvae was isolated with Trizol (Invitrogen, Cergy Pontoise, France) using the RNeasy extraction kit (Qiagen, Venlo, Netherlands) and reverse transcribed by Moloney murine leukemia virus reverse transcriptase (Promega, Madison, WI) using random hexamer primers (Promega, Madison, WI). At least three pools were analyzed for each treatment and the corresponding control. Real-time quantitative PCR (qPCR) was performed with AmpliTaq Gold polymerase in an Applied Biosystem 7500 Fast thermocycler using the standard $\mathrm{SyBr}$ Green detection protocol (Applied Biosystems, Foster City, CA). Briefly, 12 ng of total cDNA, $50 \mathrm{nM}$ (each) primers, and $1 \times \mathrm{SyBr}$ Green mixture were used in a total volume of $20 \mu \mathrm{L}$. The results were analyzed using the $\beta$-actin cDNA amplification as internal standard and fold-change was calculated relative to untreated control using the $\Delta \Delta \mathrm{Ct}$ method [24]. qPCR analysis on each RNA sample was performed in triplicate and one representative result out of at least three independent experiments is shown.

The PCR primers are described below. $\beta$-actin primers: $5^{\prime}$ CAGACATCAGGGAGTGATGG-3' (forward) and 5'-ATGGGGTATTTGAGGGTCAG-3' (reverse). uchl1 primers: 5'-GCTCTTCCCTTTAACGCAAC-3' (forward) and 5'-CCACAGGAGTTGACCACAGT-3' (reverse). hsp70 primers: 5'CCGAAGAGAAGCGACTTGAC-3' (forward) and 5'-GCGATTCCTTTTGGAGAAGAC-3' (reverse). gst-pi primers: 5'-TCCCTACACACTCACATACTT-3' (forward) and 5'-CAAAGGTCACCAGGTTCTCC-3' (reverse). mmp13 primers: 5'TCAAGGTGTCTGGAAAGCTG-3' (forward) and 5'-AGGCCTTGATGTCTGGAACT-3' (reverse).

\subsection{Statistical analysis}

All statistical analyses were performed using Graphpad prism for Windows (version 5.03) LC50, LC10, EC50 and EC10 were calculated by plotting the surviving/affected larvae against the log transformed tested concentration and the obtained curve was fitted to a sigmoidal concentration-response relation according to the following equation:

$Y=\frac{\text { Bottom }+(\text { Top }- \text { Bottom })}{1+10^{\log \text { EC50-x }}}$

where bottom and top represent, respectively, the lowest and the highest $y$-value (\% survivors/affected). The resulting calculated $\log \mathrm{EC} / \mathrm{LC}$ were extracted and their corresponding S.D. (suppl Table 1).

The decrease/increase of heartbeat, locomotion and gene expression were analyzed using one-way ANOVA followed by Dunnett's multiple comparison test [25]. Significance was considered when $P$ values were lower than 0.05 for heart rate, behavior and qPCR. ${ }^{* * *}$ Indicates statistical significance $P<0.005,{ }^{* *} P<0.01,{ }^{*} P<0.05$. Results are expressed as mean \pm S.D.

\section{Results and discussion}

Treatment with the different psychotropic drugs was initiated at $48 \mathrm{hpf}$ and the zebrafish embryos were exposed for $24 \mathrm{~h}$. After that, the drugs were washed away and the embryos were analyzed for survival and/or morphological defects either immediately or after a defined period in uncontaminated medium. In addition, various additional end-points were analyzed at the most appropriate stages in each case. The results presented in this paper were obtained in triplicate on at least 25 embryos per point. Each experiment was performed at least three times.

\subsection{Lethal concentrations of psychotropic compounds}

While no effect on survival was observed at any time point following exposure to $1 \%$ ethanol, the highest concentration of solvent used in these experiments, exposure of zebrafish embryos to psychotropic molecules resulted in decreased survival depending on the concentration of the specific compound. Survival rates were first analyzed at $1 \mathrm{dpttt}$ ( $3 \mathrm{dpf}$ ) for several concentrations in the 
A.

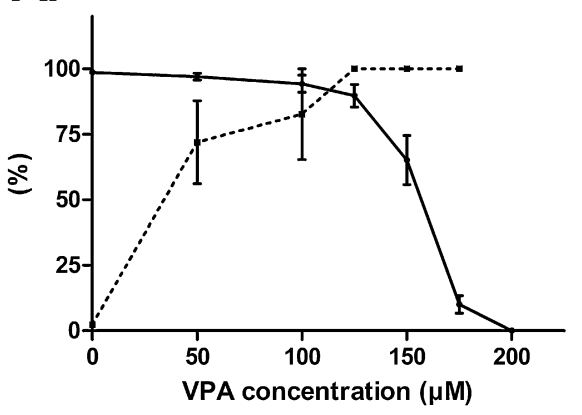

c.

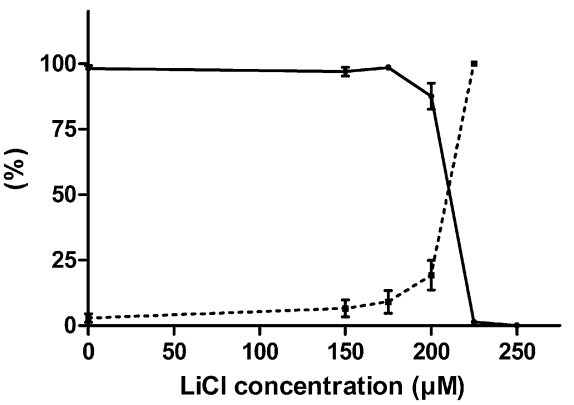

E.

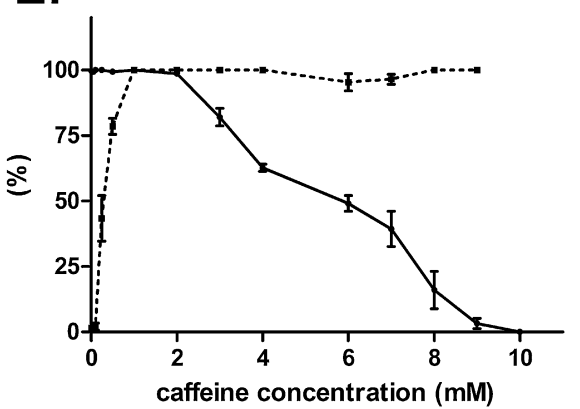

B.

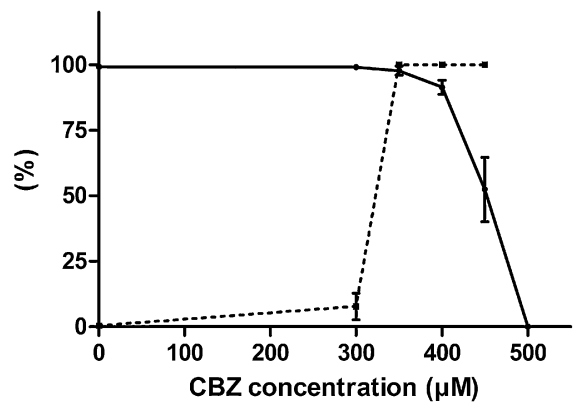

D.

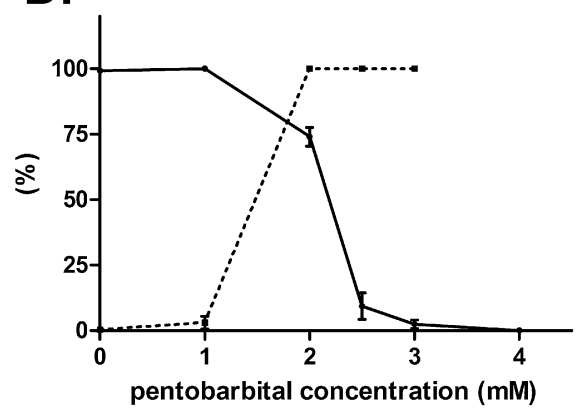

F.

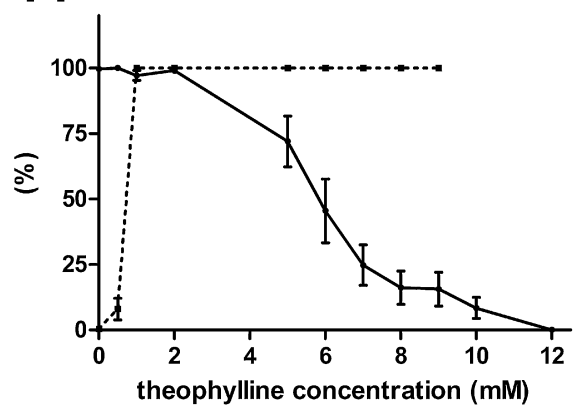

Fig. 1. Survival and morphological defects of larvae 1 day after exposure to psychotropic drugs. Fraction of surviving larvae or larvae presenting any morphological defect at $3 \mathrm{dpf}$ upon exposure to VPA (A), CBZ (B), LiCl (C), pentobarbital (D), caffeine (E) and theophylline (F) psychotropic drugs for $24 \mathrm{~h}$. Experiments were performed at least in triplicate with each time $n=25$ larvae per point. Fraction of larvae presenting morphological defects are represented in dotted lines.

medium (Fig. 1) and LC50-48/72 was determined for each compound (Fig. 1, Table 1 and suppl. Table 1). LC50-48/72 for VPA, CBZ, $\mathrm{LiCl}$, pentobarbital, caffeine and theophylline were, respectively, $155 \mu \mathrm{M}, 444 \mu \mathrm{M}, 208 \mu \mathrm{M}, 2.15 \mathrm{mM}, 5.18 \mathrm{mM}$ and $5.8 \mathrm{mM}$, as summarized in Table 1 . The results of our survival tests clearly show that all the compounds are lethal to zebrafish larvae at various concentrations.

The surviving larvae were further incubated in fresh, uncontaminated E3 medium at $28^{\circ} \mathrm{C}$ for $72 \mathrm{~h}$ and reanalyzed for delayed lethality at $6 \mathrm{dpf}$ (Fig. 2). Lethal concentrations, defined as LC5048/144, were $91 \mu \mathrm{M}, 427 \mu \mathrm{M}, 179 \mu \mathrm{M}, 1.9 \mathrm{mM}, 2.7 \mathrm{mM}$ and $2.7 \mathrm{mM}$, respectively, for VPA, CBZ, LiCl, pentobarbital, caffeine and theophylline, as reported in Table 1. LC50 values for delayed lethality were lower for each of the compounds tested here, although the larvae were not further exposed to the toxicant.

For comparison, we also determined the lethal concentrations of these compounds at early developmental stages by starting the treatment of the embryos at $4 \mathrm{hpf}$ and evaluating survival at 24 and $48 \mathrm{hpf}$. The corresponding LC50-4/24 and LC50-4/48 values are, respectively, $1.1 \mathrm{mM}$ and $1 \mathrm{mM}$ for VPA or $212 \mu \mathrm{M}$ and $181 \mu \mathrm{M}$ for CBZ (Table 1), while LiCl, pentobarbital and theophylline exerted only minimal effects at the highest tested concentration (higher than 20, 10 and $25 \mathrm{mM}$, respectively, see also Table 1 ). Only caffeine appears to induce similar (LC50-4/24 = $5 \mathrm{mM}$ and LC50-4/48 = $5 \mathrm{mM}$ versus LC50-48/72 $=5.173 \mathrm{mM}$ ) toxicity in earlier larvae compared to 2-days old animals. Thus, comparison of lethal concentrations at later stages (LC50-48/72 or LC50-48/144) to those determined at early stages (LC50-4/24 and LC50-4/48) reveals that early developmental stages display a much lower sensitivity to 4 out of 6 compounds tested here.

\subsection{Morphological defects}

To assess the developmental defects caused in the zebrafish larvae by exposure to these psychotropic molecules, embryos were treated with different concentrations of each compound at $48 \mathrm{hpf}$ and assessed 1 day later ( $3 \mathrm{dpf}$ ) for occurrence of morphological defects. While precluding the possibility to observe early developmental effects, we concentrated on perturbations during later life stages such as dorsal curvature (DC), pericardial edema (PE), yolk sac edema (YE), hemorrhage or altered size (Fig. 3). The fraction of the surviving embryos presenting one of the described morphological abnormalities was determined (Figs. 1 and 2) for the different concentrations of each compound; representative pictures are shown (Fig. 3). 
Table 1

Molecules tested and their effects on lethality.

\begin{tabular}{|c|c|c|c|c|c|c|c|}
\hline & & LC50-4/24 & LC50-4/48 & LC50-48/72 & LC10-48/72 & LC50-48/144 & LC10-48/144 \\
\hline Valproic acid & & $1.1 \mathrm{mM}$ & $1.02 \mathrm{mM}$ & $155 \mu \mathrm{M}$ & $135 \mu \mathrm{M}$ & $91 \mu \mathrm{M}$ & $67 \mu \mathrm{M}$ \\
\hline Carbamazepine & & $212 \mu \mathrm{M}$ & $181 \mu \mathrm{M}$ & $444 \mu \mathrm{M}$ & $339 \mu \mathrm{M}$ & $427 \mu \mathrm{M}$ & $401 \mu \mathrm{M}$ \\
\hline Lithium chloride & $\mathrm{LiCl}$ & $>20 \mathrm{mM}$ & $>20 \mathrm{mM}$ & $208 \mu \mathrm{M}$ & $199 \mu \mathrm{M}$ & $179 \mu \mathrm{M}$ & $173 \mu \mathrm{M}$ \\
\hline Pentobarbital & & $>10 \mathrm{mM}$ & $>10 \mathrm{mM}$ & $2.147 \mathrm{mM}$ & $1.848 \mathrm{mM}$ & $1.885 \mathrm{mM}$ & $1.538 \mathrm{mM}$ \\
\hline Caffeine & & $5 \mathrm{mM}$ & $5 \mathrm{mM}$ & $5.173 \mathrm{mM}$ & $2.551 \mathrm{mM}$ & $2.687 \mathrm{mM}$ & $2.321 \mathrm{mM}$ \\
\hline Theophylline & & $>25 \mathrm{mM}$ & $>25 \mathrm{mM}$ & $5.845 \mathrm{mM}$ & $3.781 \mathrm{mM}$ & $2.678 \mathrm{mM}$ & $1.308 \mathrm{mM}$ \\
\hline
\end{tabular}

The table shows the name and chemical structure of the different pharmaceuticals tested here. LC50 and LC10 were obtained under the different conditions (treatment starting at 4 hpf, observation at 24 hpf: LC50-4/24; observation at 48 hpf: LC50-4/48 and treatment from 48 to 72 hpf, observation at 72 hpf: $48 / 72$; observation at 144 hpf: 48/144).

Developmental defects were first analyzed at $1 \mathrm{dpttt}(3 \mathrm{dpf})$ (Fig. 1) and EC50-48/72 and EC10-48/72 were determined for each compound (Fig. 1, Table 2 and suppl. Table 1). EC50-48/72 for VPA, $\mathrm{CBZ}, \mathrm{LiCl}$, pentobarbital, caffeine and theophylline were, respectively, $33 \mu \mathrm{M}, 305 \mu \mathrm{M}, 232 \mu \mathrm{M}, 1.096 \mathrm{mM}, 286 \mu \mathrm{M}$ and $535 \mu \mathrm{M}$ as summarized in Table 2.

Defects induced by VPA have been previously studied on zebrafish larvae and adults and are very often correlated with its ability to inhibit histone deacetylases (HDACs) [26-28]. Absence or serious delays in liver, exocrine pancreas [27] and blood vessel development $[27,29]$ as well as defects in hematopoiesis [26] were observed using transgenic zebrafish lines or in situ hybridization experiments. Teratogenic effects such as hatching retardation and axial malformation [30] were also described. Our results show that all VPA treated, morphologically affected larvae presented edema, half of these were pericardial edema (PE), while the fraction of animals also exhibiting hemorrhages increased from $49 \%$ at $50 \mu \mathrm{M}$ to $90 \%$ at $100 \mu \mathrm{M}$ or higher concentrations of VPA.
CBZ was previously shown to cause growth retardation at $423 \mu \mathrm{M}$ and heart deformities at $846 \mu \mathrm{M}$ [31] in $72 \mathrm{hpf}$ zebrafish larvae after 3 days continuous exposure, while a decrease in swimming speed and an increase in the time to eat midge larvae was observed in mature medaka after 8-9 days exposure to $26 \mu \mathrm{M}$ [32]. In our experiments, the fraction of CBZ treated larvae displaying edema increased from $7.7 \%$ of the survivors at $300 \mu \mathrm{M}$ to $100 \%$ above $350 \mu \mathrm{M}$, while the fraction also presenting hemorrhages increased from $33 \%$ at $350 \mu \mathrm{M}, 58 \%$ at $400 \mu \mathrm{M}$ to $48 \%$ at $450 \mu \mathrm{M}$. $\mathrm{LiCl}$ was shown to inhibit the phosphoinositide signaling pathway in many cells and to severely disrupt axis determination, mesoderm induction and patterning in early embryos [33-35]. Here we observed that the major defect caused by LiCl treatment was dorsal curvature (DC). No teratogenic effect was previously described for pentobarbital, however in our experiments pentobarbital exposure lead to edema and hemorrhages in all the survivors at concentrations above $2 \mathrm{mM}$.

Table 2

Molecules tested and their effects on morphology.

\begin{tabular}{llllllll}
\hline & EC50-48/72 & EC10-48/72 & EC50-48/144 & EC10-48/144 & TI 48/72 & TI 48/144 Defects \\
\hline Valproic acid & $33 \mu \mathrm{M}$ & $13 \mu \mathrm{M}$ & $31 \mu \mathrm{M}$ & $19 \mu \mathrm{M}$ & 4.66 & 2.97 & Pericardial edema dorsal curvature smaller tail \\
Carbamazepine & $305 \mu \mathrm{M}$ & $301 \mu \mathrm{M}$ & $>450 \mu \mathrm{M}$ & $326 \mu \mathrm{M}$ & 1.46 & $<1$ & Dorsal curvature pericardial edema \\
Lithium chloride & $232 \mu \mathrm{M}$ & $180 \mu \mathrm{M}$ & $151 \mu \mathrm{M}$ & $148 \mu \mathrm{M}$ & 0.89 & 1.19 & Pericardial edema dorsal curvature \\
Pentobarbital & $1.096 \mathrm{mM}$ & $1.041 \mathrm{mM}$ & $>2$ & $>2$ & 1.96 & $<1$ & Pericardial edema \\
Caffeine & $286 \mu \mathrm{M}$ & $126 \mu \mathrm{M}$ & $4.919 \mathrm{mM}$ & $1.241 \mathrm{mM}$ & 18.08 & 0.55 & Larval size pericardial edema \\
Theophylline & $535 \mu \mathrm{M}$ & $505 \mu \mathrm{M}$ & $2.507 \mathrm{mM}$ & $1.346 \mathrm{mM}$ & 11.58 & 1.068 & Larval size pericardial edema hemorrhage
\end{tabular}

The table shows effective concentrations obtained under the different conditions (treatment from 48 to 72 hpf, observation at 72 hpf: EC50-48/72 and EC10-48/72; observation at 144 hpf: EC50-48/144 and EC10-48/144), teratogenic index and morphological defects that were observed for each drug. 
A.

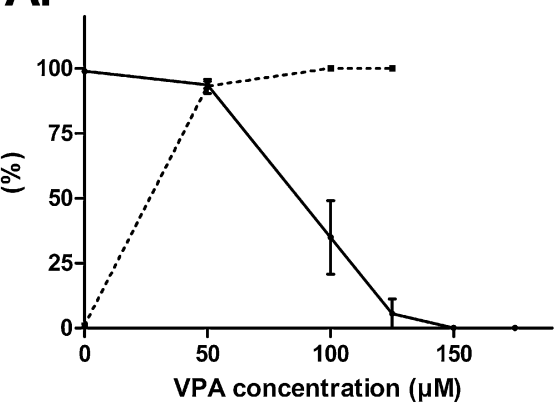

C.

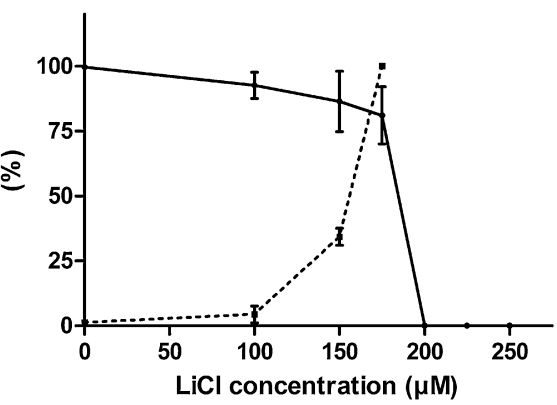

E.

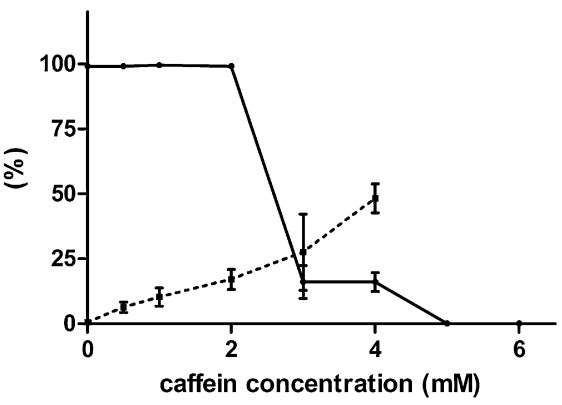

B.

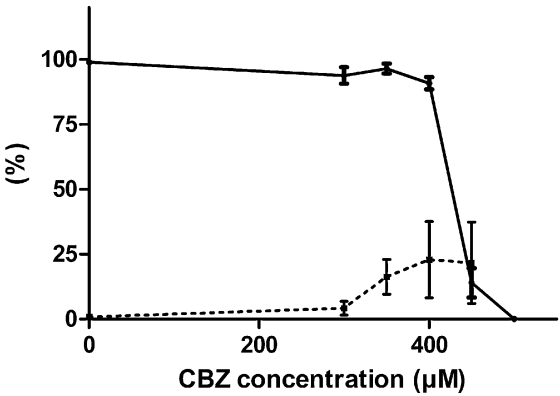

D.

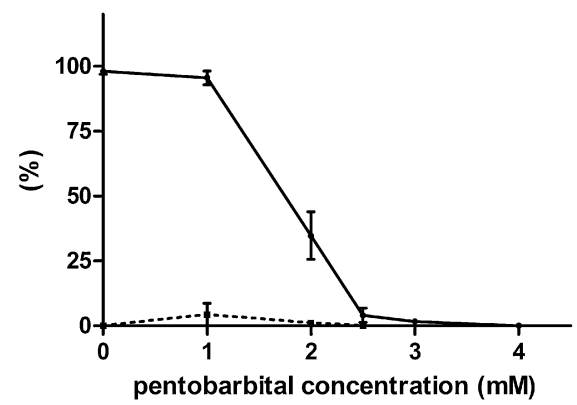

F.

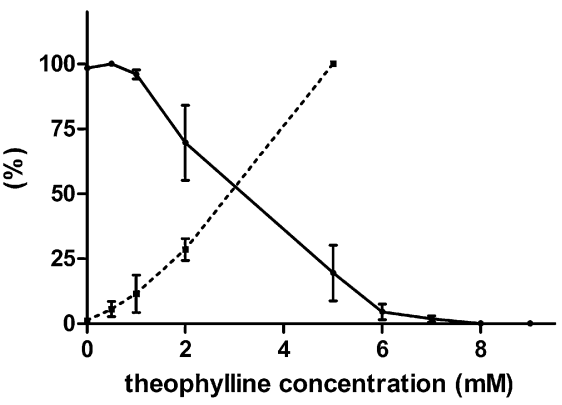

Fig. 2. Survival and morphological defects of larvae 3 days after exposure to psychotropic drugs. Fraction of surviving larvae or larvae presenting any morphological defect at $6 \mathrm{dpf}$ upon exposure to VPA (A), CBZ (B), $\mathrm{LiCl}$ (C), pentobarbital (D), caffeine (E) and theophylline (F) psychotropic drugs for $24 \mathrm{~h}$ from 48 hpf to $72 \mathrm{hpf}$. Experiments were performed at least in triplicate with each time $n=25$ larvae per point. Fraction of larvae presenting morphological defects are represented in dotted lines.

For caffeine, a kinked tail was described upon acute exposure in 2-3 days old embryos [36], while a shorter body length and reduced tactile reflex was observed in $24-48 \mathrm{hpf}$ embryos after prolonged exposure [37]. In our experimental setup, we observed that caffeine induced shorter tails at $0.25 \mathrm{mM}$ and dorsal curvature at $0.5 \mathrm{mM}$ in all (96.8\%) surviving larvae. At $3 \mathrm{mM}$, additional edema and hemorrhages were also observed (about $30 \%$ of surviving larvae presented both alterations), while at higher concentrations all survivors presented edema.

Toxic effects of theophylline have been scarcely studied on zebrafish larvae. In our experiments, exposure to theophylline led to a smaller size or curved tail in $5 \%$ of the survivors at $0.5 \mathrm{mM}$ (66\% of affected larvae). A significant fraction of affected larvae also displayed edema at $2 \mathrm{mM}$ (3\%), $5 \mathrm{mM}(53 \%)$ or $6 \mathrm{mM}$ (100\%).

The teratogenic index (TI48-72) was also calculated as LC50/EC50. While the effects observed with $\mathrm{LiCl}(\mathrm{TI}=0.89)$ and possibly $\mathrm{CBZ}(\mathrm{TI}=1.46)$ and pentobarbital $(\mathrm{TI}=1.96)$ may be closely related to their lethality, VPA $(\mathrm{TI}=4.66)$, caffeine $(\mathrm{TI}=18.08)$ and theophylline $(\mathrm{TI}=11.58)$ clearly revealed their teratogenicity $(\mathrm{TI} \gg 1)$.

The surviving larvae were further incubated in fresh, uncontaminated E3 medium at $28^{\circ} \mathrm{C}$ and reanalyzed for delayed morphological effects at $6 \mathrm{dpf}, 3$ days after removing the various chemicals (Fig. 2) and EC50-48/144 were calculated (Table 2). Two different situations appeared in these tests. For VPA, the fraction of abnormal larvae was similar or slightly increased at the lowest tested concentration $(50 \mu \mathrm{M})$, while for all the other substances this fraction was largely decreased or even absent in the case of pentobarbital (Fig. 2D). This was not always due to the fact that morphologically affected larvae died during the additional 3 days period, as best illustrated by the treatment with caffeine $0.5 \mathrm{mM}$ where close to all the larvae suffered from shorter tails and body curvature at $3 \mathrm{dpf}$, while no lethality was observed at $6 \mathrm{dpf}$. Rather, the increased incidence at $3 \mathrm{dpf}$ of edema and hemorrhages with concentrations higher than $3 \mathrm{mM}$ could correlate with late lethality. A similar observation holds true for 1 or $2 \mathrm{mM}$ theophylline or $2 \mathrm{mM}$ pentobarbital. With VPA, edema and hemorrhages observed at $50 \mu \mathrm{M}$ did not lead to late lethality, however the fraction of similarly affected larvae increased to $100 \%$, suggesting a longer delay in lethality in this case.

Thus, drug treatment from 48 to $72 \mathrm{hpf}$ led to clear morphological malformations such as body curvature and slower growth that were partially reversible upon withdrawal, while edema and hemorrhages appear to mostly lead to delayed lethality. 
A

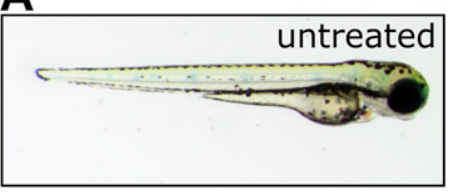

B

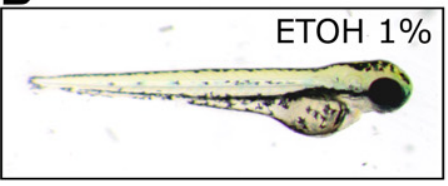

C

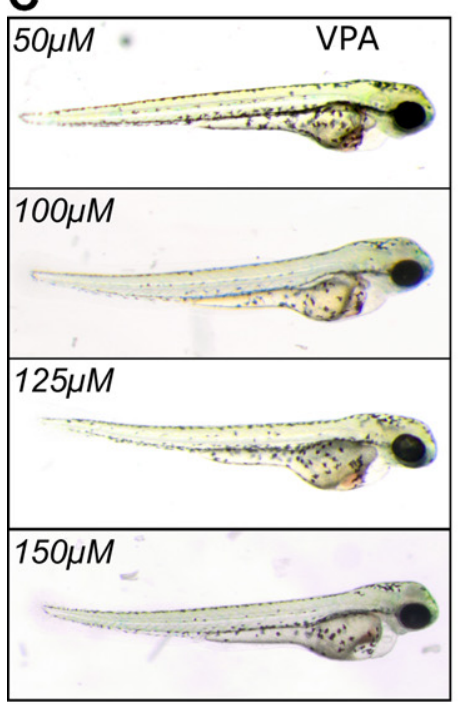

$\mathbf{F}$

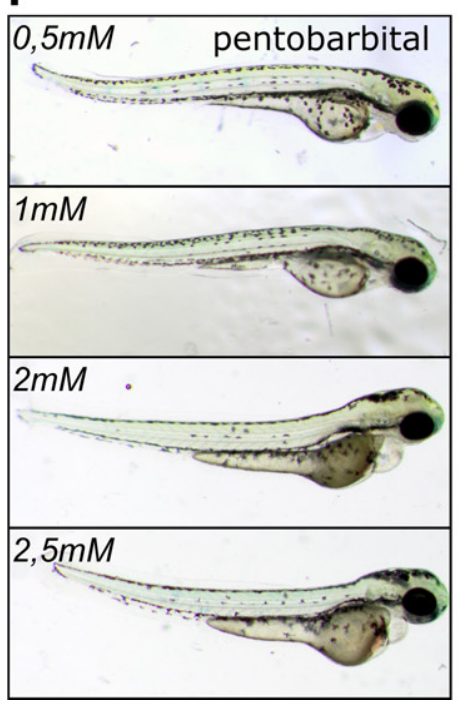

D

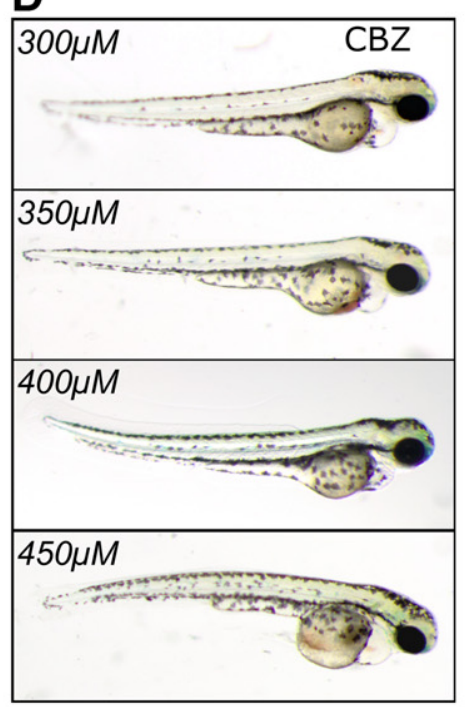

G

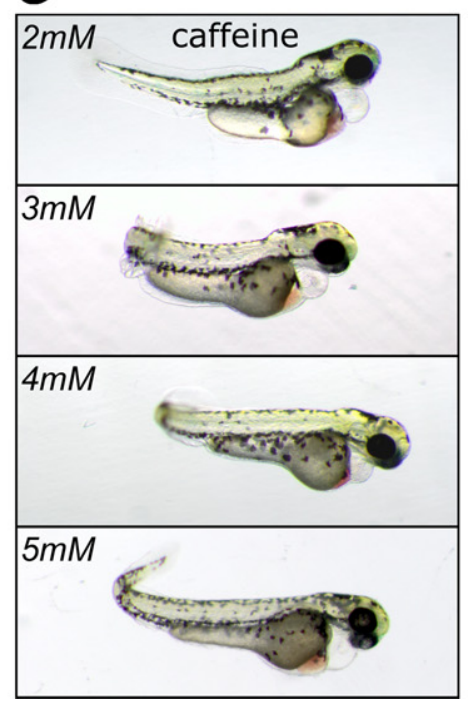

E

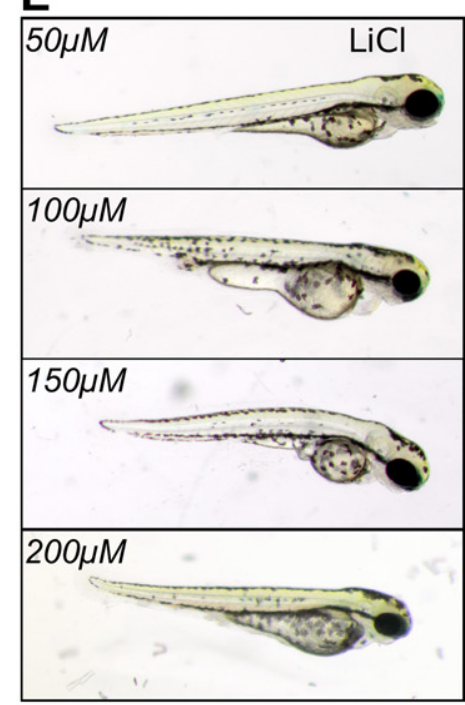

$\mathrm{H}$

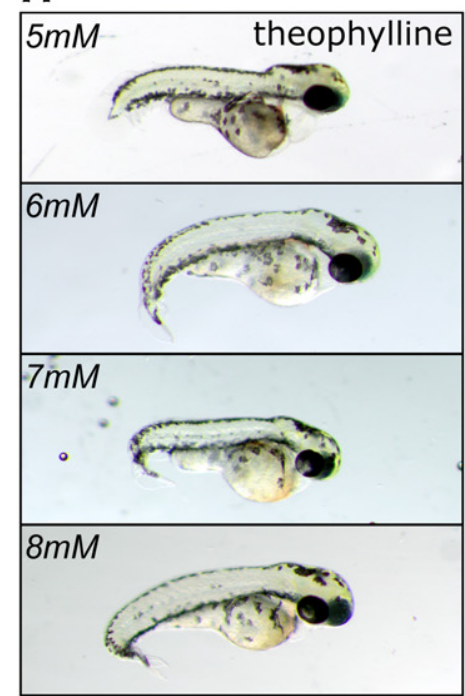

Fig. 3. Morphological defects after $24 \mathrm{~h}$ of exposure. Representative images of $3 \mathrm{dpf}$ larvae after 1 day exposure to psychotropic drugs at the indicated concentrations: untreated (A), ethanol 1\% (B), VPA (C), CBZ (D), $\mathrm{LiCl}(\mathrm{E})$, pentobarbital (F), caffeine (G) and theophylline (H).

\subsection{Heart beat analysis}

To assess the effects of psychotropic molecules on zebrafish physiology, we also analyzed the heart rate at $3 \mathrm{dpf}$, immediately after the different $24 \mathrm{~h}$ treatments in the surviving individuals (Fig. 4). A dramatic decrease in cardiac rhythm was observed upon VPA treatment $(31-53 \mathrm{bpm}$ compared to $165 \pm 12 \mathrm{bpm}$ for untreated larvae) (Fig. 4A) at all concentrations tested $(50-150 \mu \mathrm{M})$. CBZ treated larvae exhibit a significant and concentration-dependent decrease of heart rate (from $175 \pm 13$ in controls to $140 \pm 22$ at $350 \mu \mathrm{M}, 89 \pm 18$ at $400 \mu \mathrm{M}$ and $75 \pm 16 \mathrm{bpm}$ at $450 \mu \mathrm{M}$ ), while no significant difference was observed for ETOH $1 \%$ exposed larvae $(157 \pm 4)$ (Fig. $4 \mathrm{~B}$ ). $\mathrm{LiCl}$ exposure caused a decreased heart rate from $184 \pm 9$ in controls to $165 \pm 9,144 \pm 8$, $138 \pm 9$ and $63 \pm 18 \mathrm{bpm}$, respectively, in $50 \mu \mathrm{M}, 100 \mu \mathrm{M}, 150 \mu \mathrm{M}$ and $200 \mu \mathrm{M}$ treated larvae (Fig. 4C), while pentobarbital exposure led to heart rate decrease at high concentrations such as $1 \mathrm{mM}$ $(140 \pm 33)$ and $2 \mathrm{mM}(84 \pm 12)$ (Fig. 4D). Anxiogenic treatments such as caffeine are among the best-studied drugs concerning their effects on heart rate. In humans, acute administration is often associated with an increased heart rate [38], however a decrease has also been documented [39-41]. An increased [42] or decreased [36] heart rate has also been previously described in zebrafish. The reasons for this discrepancy are unclear. In our experiments, we observed a dose-dependent decrease by caffeine at 3, 4 and $5 \mathrm{mM}$ $(122 \pm 25 ; 90 \pm 28$ and $85 \pm 17$ compared to control $179 \pm 9 \mathrm{bpm})$ 
A.

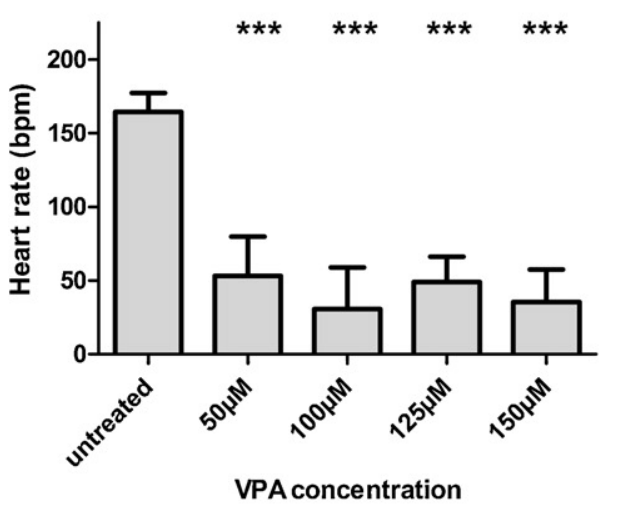

C.

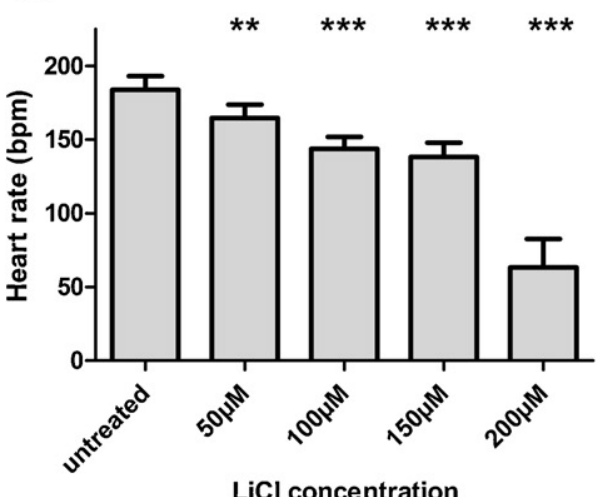

E.

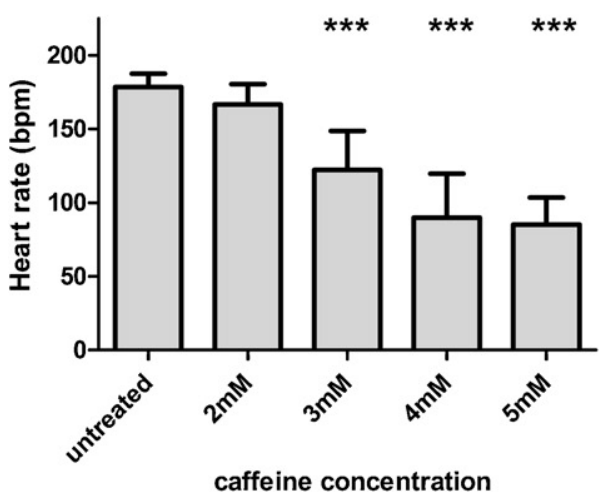

B.

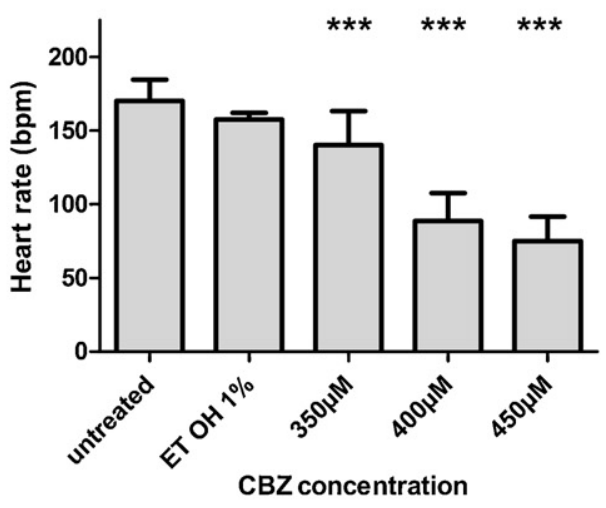

D.

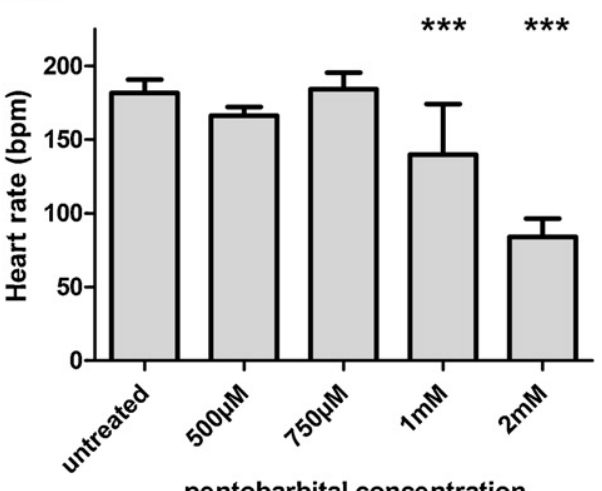

pentobarbital concentration

F.

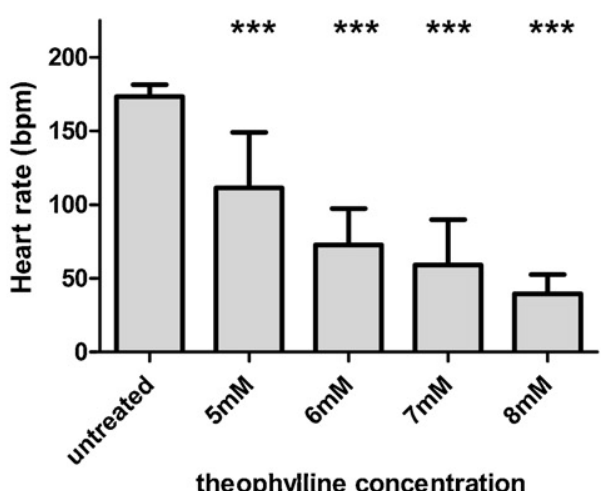

Fig. 4. Psychotropic drugs effects on zebrafish larvae cardiac activity. Cardiac activity was determined by counting the heart rate of VPA (A), CBZ (B), LiCl (C), pentobarbital (D), caffeine (E) and theophylline (F) exposed and non exposed larvae and represented in beats per min. The results were obtained on at least 10 larvae from at least three independent experiments. ${ }^{* *}$ Statistical significance $P<0.005,{ }^{* *} P<0.01,{ }^{*} P<0.05$.

(Fig. 4E) and theophylline 5, 6, 7 and $8 \mathrm{mM}(111 \pm 36 ; 73 \pm 24$; $59 \pm 30$ and $40 \pm 12$ compared to control $173 \pm 8$ bpm) (Fig. $4 \mathrm{~F}$ ).

Thus, a single and easily accessible end-point such as heart rate is able to predict alterations leading to death in treated embryos, mostly at sublethal concentrations and without predicting the exact type of alteration.

\subsection{Locomotor defects}

To analyze the effect of psychotropic drugs on zebrafish larvae locomotion, the movements of control and treated larvae were recorded at $6 \mathrm{dpf}$, i.e. 3 days after terminating the treatment. We determined the activity (Fig. 5), corresponding to the fraction of time spent in locomotion (in \%), and velocity (Fig. 6), corresponding to the total distance covered by the small movements relative to the duration of the movements (in $\mathrm{mm} / \mathrm{s}$ ). A decrease in activity of the larvae was observed after exposure to VPA at $50 \mu \mathrm{M}(a=12 \pm 14)$, $100 \mu \mathrm{M}(a=0.04 \pm 0.04)$ and $125 \mu \mathrm{M}(1 \pm 2)$ when compared to untreated larvae $(38 \pm 14)$, which is paralleled by a decrease in velocity (respectively, $0.3 \pm 0.3 ; 0 \pm 0 ; 0 \pm 0.1$ and $0.7 \pm 0.3$ ). $\mathrm{LiCl}$ exposure at $150 \mu \mathrm{M}$ also led to a decrease of activity (18 \pm 20$)$ and of velocity $(0.4 \pm 0.4)$ when compared to untreated larvae (respectively, $33 \pm 10$ and $0.8 \pm 0.2$ ). Caffeine is known to induce strong behavioral effects on adult zebrafish after acute exposure, such as stress and anxiety [43] or habituation responses [44]. Caffeine and theophylline at $2 \mathrm{mM}$ cause a significant decrease of activity (from 
a.

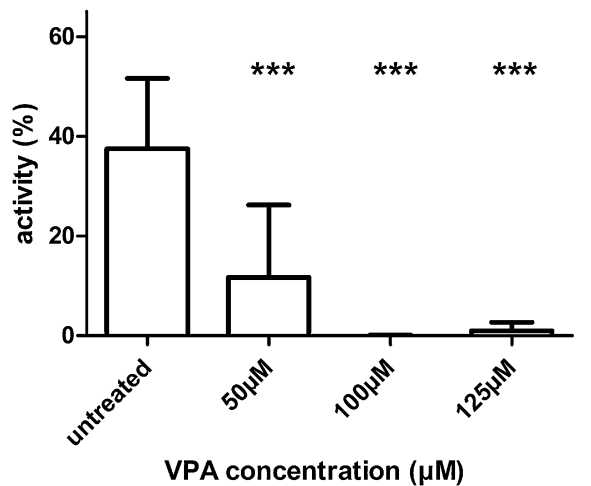

c.

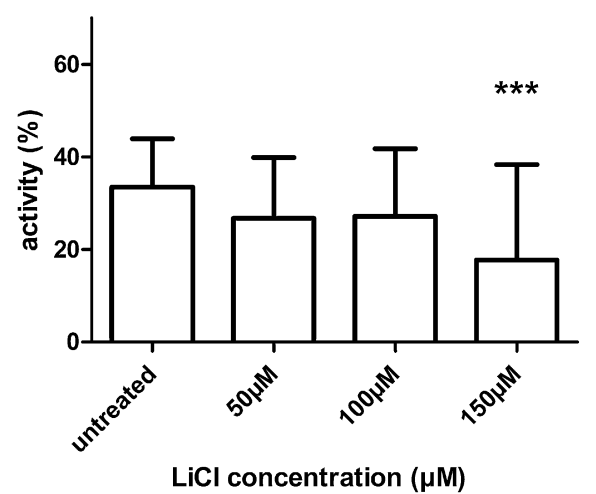

e.

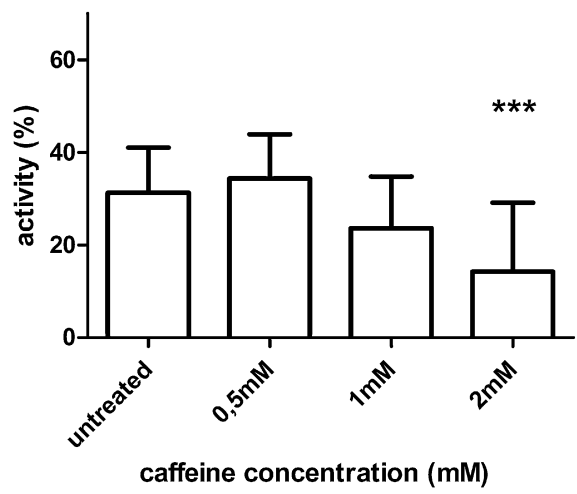

b.

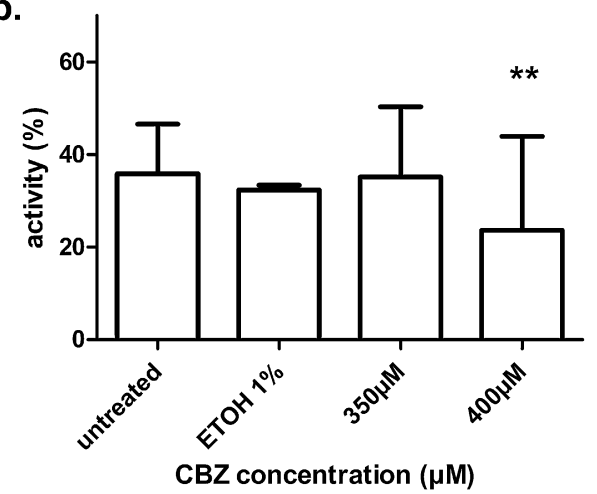

d.

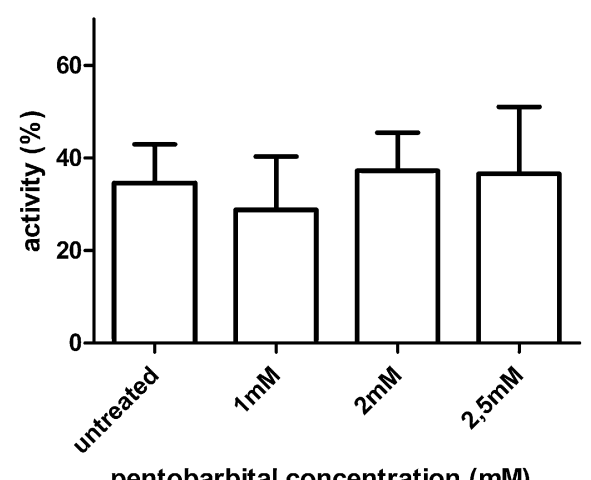

pentobarbital concentration (mM)

f.

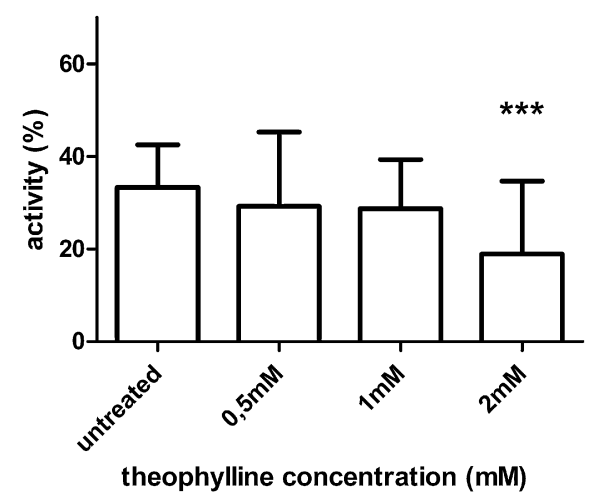

Fig. 5. Effects of drug exposure on locomotor activity at 6 dpf. Activity was determined for VPA (A), CBZ (B), LiCl (C), pentobarbital (D), caffeine (E) and theophylline (F) exposed larvae. 2-Day-old larvae were exposed for $24 \mathrm{~h}$ to the indicated drug at different concentrations and 4 day after drug exposure, larvae movement was analyzed. Activity was calculated according to the manufacturer's instructions. Measurements were performed on at least 8 larvae, in 1 min intervals during 30 min, and at least in triplicate. Activity corresponds to the fraction of time spent in locomotion during each 1 min interval. ${ }^{* * *}$ Statistical significance $P<0.005,{ }^{* *} P<0.01,{ }^{*} P<0.05$.

untreated $31 \pm 10$ and $33 \pm 9$ to, respectively, $14 \pm 15$ and $19 \pm 16)$ associated with a similar effect on velocity $(0.3 \pm 0.3$ and $0.5 \pm 0.3)$ when compared to untreated $(0.7 \pm 0.2$ and $0.8 \pm 0.1)$. A decrease of activity and velocity was observed for $400 \mu \mathrm{M} \mathrm{CBZ}$ treated larvae $(23 \pm 20$ and $0.5 \pm 0.3)$ when compared to untreated larvae $(36 \pm 11$ and $0.8 \pm 0.2$ ) while no significant locomotor effect was observed for pentobarbital and ethanol $1 \%$ treated larvae. Pentobarbital has been shown to promote a sleep-like behavior in adult zebrafish and a decrease of spontaneous (locomotor) activity in zebrafish larvae at concentrations ranging from 0.1 to $65 \mu \mathrm{M}[45,46]$ between $20 \mathrm{~min}$ and $2 \mathrm{~h}$ after administration, our data indicate that these effects are undetectable 3 days after terminating the treatment, even at much higher concentrations.

Thus, only VPA induced a dramatic decrease in activity and velocity at the lowest concentration, while $\mathrm{CBZ}$, $\mathrm{LiCl}$, caffeine and theophylline caused a significant effect only at the highest concentrations, with most larvae presenting morphological defects. No effect was observed for pentobarbital, which also caused no defects at this stage. Although it is unclear at present whether the observed decrease of locomotor activity is due to the observed morphological defects or to additional effects on neural development, our results suggest a correlation between altered morphology and locomotor defects. Further studies will reveal whether assessment of behavioral effects at earlier stages, such as $4 \mathrm{dpf}[47,48]$ would allow a more accurate and sensitive evaluation of biological activity.

\subsection{Gene expression}

Studying the expression of genes involved in various biological processes provides a highly sensitive test in toxicological 
a.

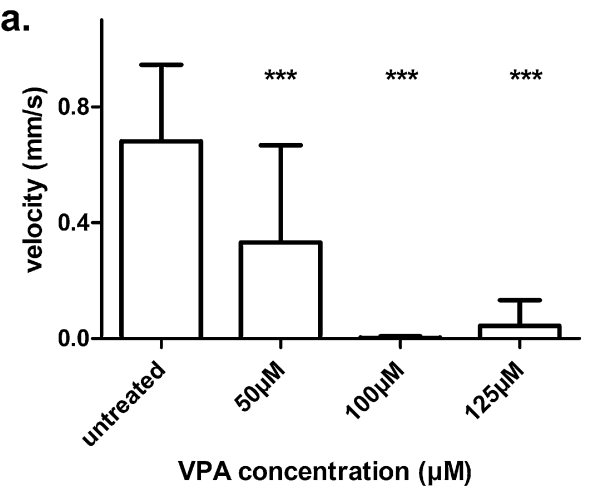

c.

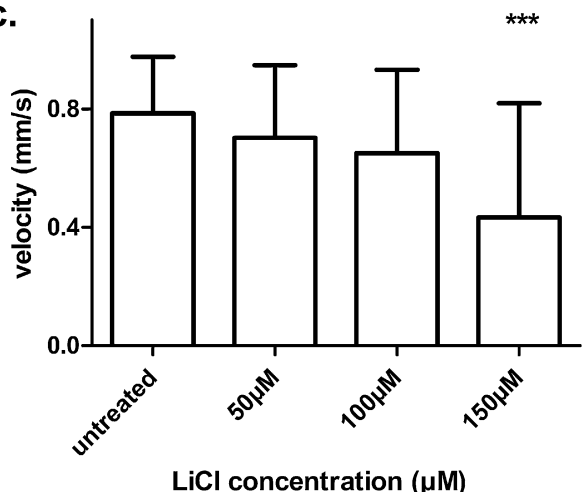

$\mathrm{LiCl}$ concentration $(\mu \mathrm{M})$

e.

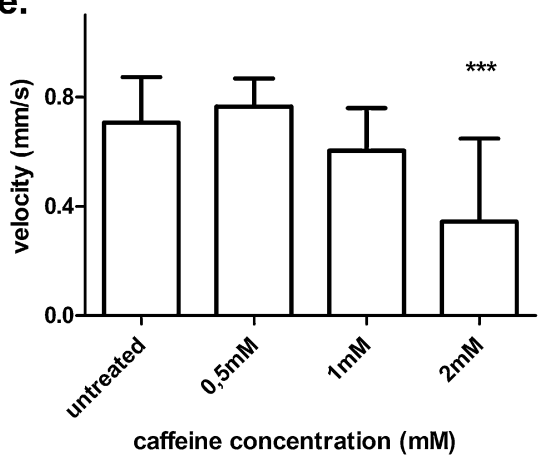

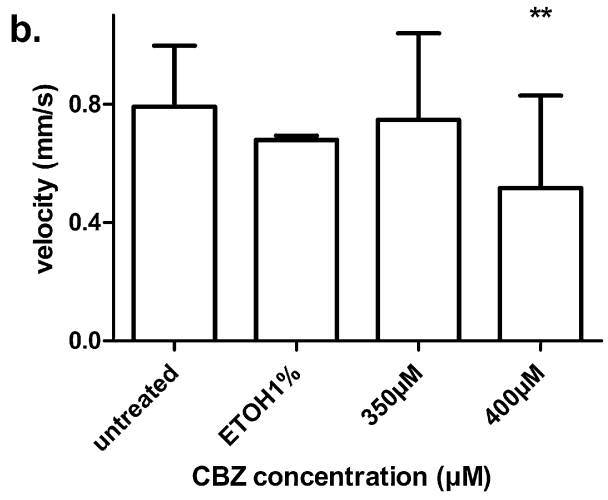

d.

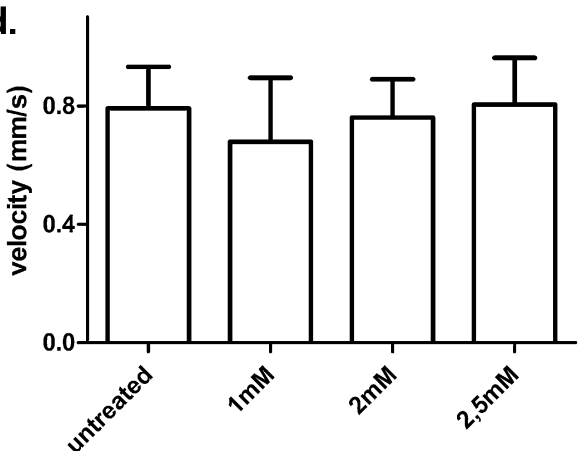

pentobarbital concentration ( $\mathrm{mM})$ f.

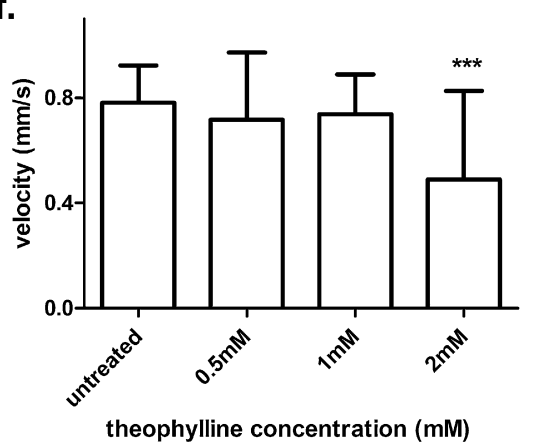

Fig. 6. Effects of drug exposure on locomotor activity at 6 dpf. Velocity was determined for VPA (A), CBZ (B), LiCl (C), pentobarbital (D), caffeine (E) and theophylline (F) exposed larvae. 2-Day-old larvae were exposed for $24 \mathrm{~h}$ to the indicated drug at different concentrations and 4 day after drug exposure, larvae movement was analyzed. Velocity was calculated according to the manufacturer's instructions. Measurements were performed on at least 8 larvae, in 1 min intervals during 30 min, and at least in triplicate. Velocity corresponds to the distance covered during small movements relative to the duration of the small movements. ${ }^{* * *}$ Statistical significance $P<0.005$, ${ }^{* *} P<0.01,{ }^{*} P<0.05$.

studies [49-51]. We analyzed genes involved in stress response (Heat shock protein 70 hsp70), detoxification (glutathione S-transferase pi gstpi), neurodegenerative diseases (ubiquitin carboxy-terminal-hydrolase L1 uchl1) and inflammation (matrix metalloprotease $13 \mathrm{mmp} 13$ ). Immediately after exposure to the psychotropic compounds for $24 \mathrm{~h}$, total RNA was extracted from control and treated larvae at $3 \mathrm{dpf}$ and the expression of these four marker genes was analyzed by qRT-PCR. Gene expressions were assessed after exposure to the previously determined EC10, EC50, LC10 and LC50 concentrations, except for $\mathrm{LiCl}$ where EC50 was higher than LC50.

Expression of the $h s p 70$ gene, associated with a proteotoxic stress response, was increased by treatments with all psychotropic molecules at relevant concentrations (Fig. 7). CBZ induced such an increase (9-fold) only for LC50 concentration. Exposure to VPA and theophylline lead to a significant increase of HSP70 expression also at LC10 (about 20-fold), while caffeine exposure lead to an increase for the three highest concentrations (from 7 to 23-fold) and increased $h s p 70$ expression was observed at all $\mathrm{LiCl}$ (from 4 to 10 -fold) and pentobarbital concentrations (from 5 to 186-fold).

Glutathione S-transferases play crucial roles in detoxification, but also in redox regulation [52]. The detoxification pathway was examined by following gstpi expression (Fig. 8) that was significantly increased after carbamazepine $444 \mu \mathrm{M}$ (6-fold), while a significant decrease was observed for $5.173 \mathrm{mM}$ caffeine exposure (4-fold) and $5.845 \mathrm{mM}$ theophylline (10-fold). 
A.

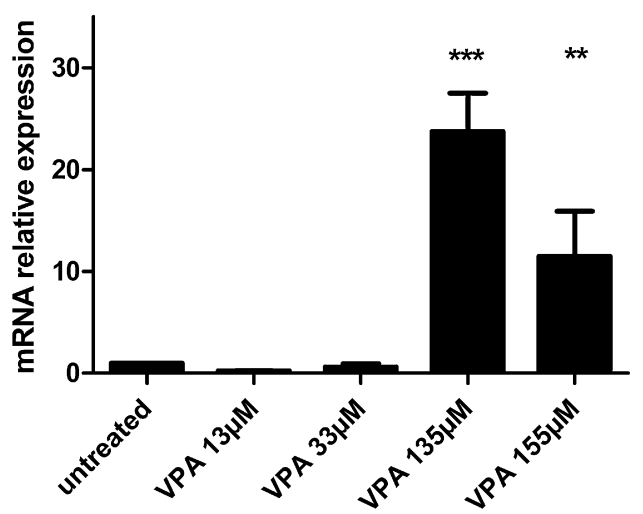

C.

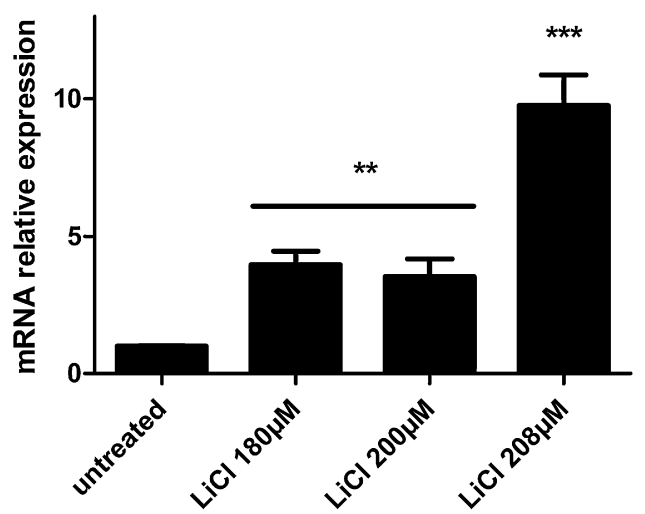

E.

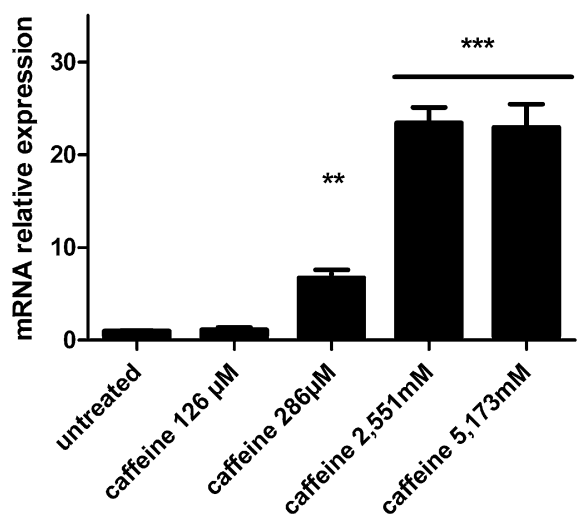

B.

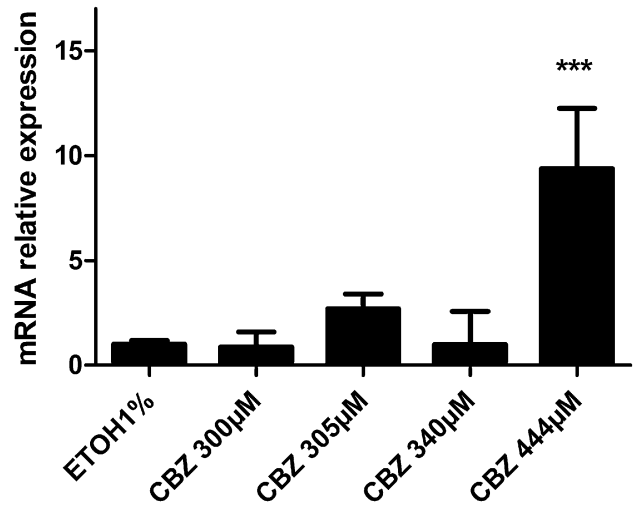

D.

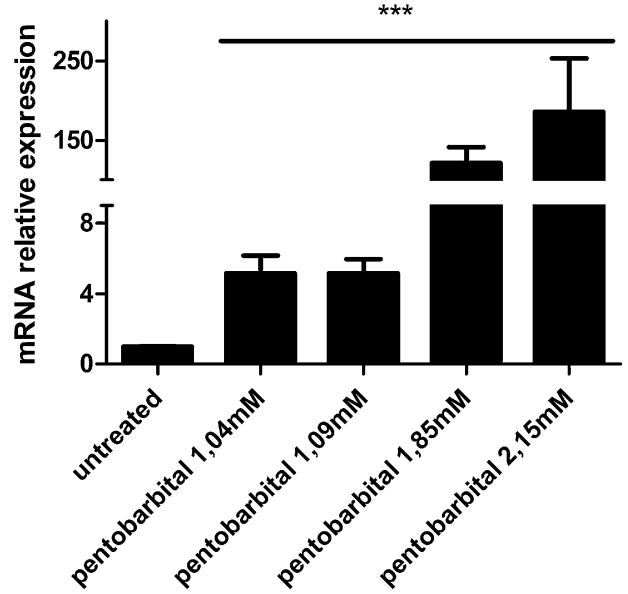

$\mathbf{F}$.

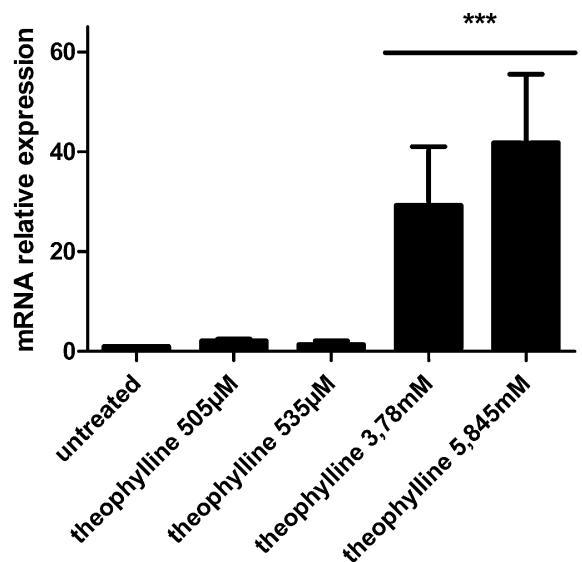

Fig. 7. $h s p 70$ expression analysis in zebrafish larvae after psychotropic agent exposure. RT-qPCR analysis was performed on total RNA from control and treated 3 dpf larvae after $24 \mathrm{~h}$ treatment with VPA (A), CBZ (B), $\mathrm{LiCl}(\mathrm{C})$, pentobarbital (D), caffeine (E) and theophylline (F). mRNA levels were determined using the zebrafish $\beta$-actin mRNA as internal standard and their expression relative to untreated controls was determined. Shown are the means \pm S.D. of one representative from three independent experiments. ${ }^{* * *}$ Statistical significance $P<0.005,{ }^{* *} P<0.01,{ }^{*} P<0.05$. 

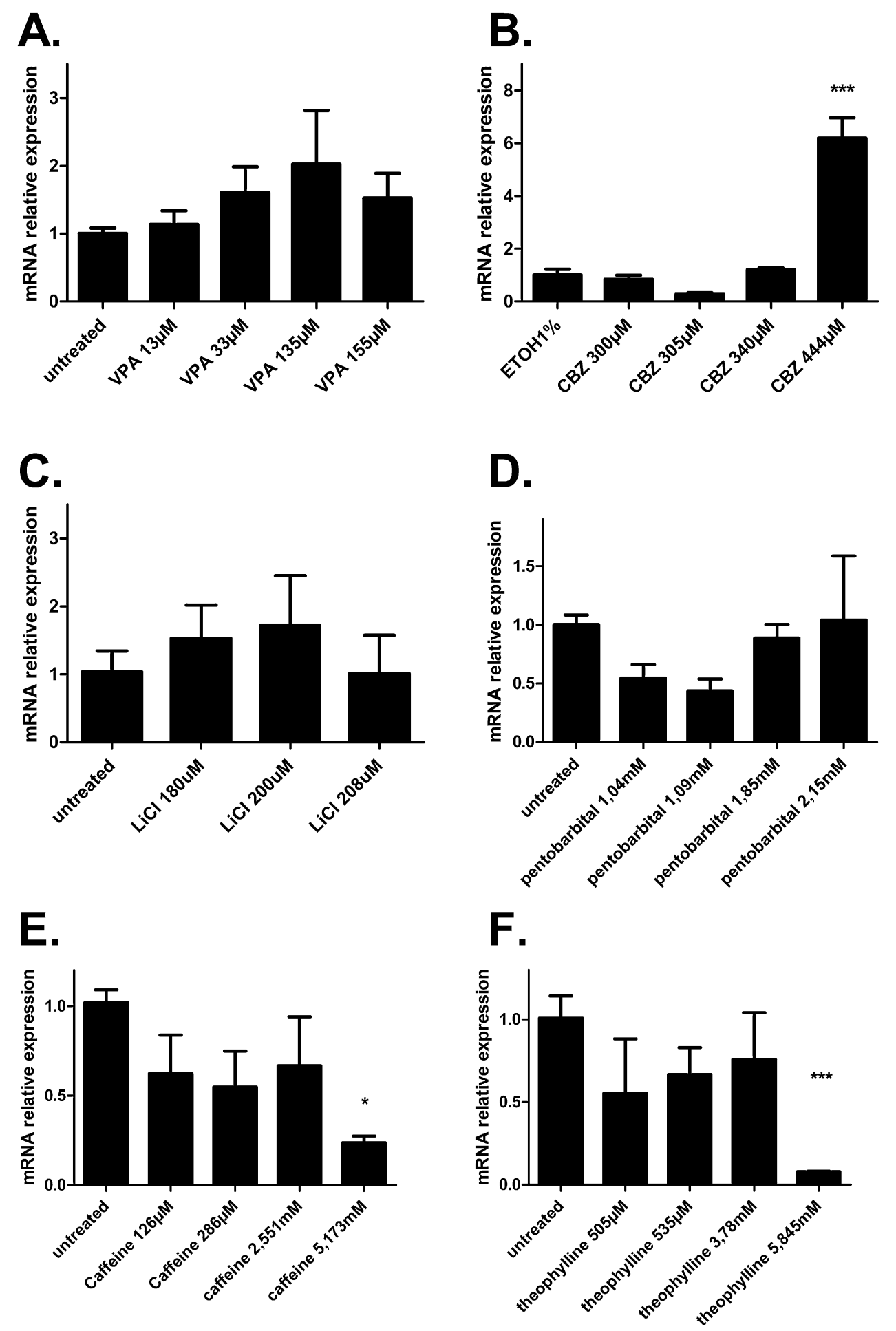

Fig. 8. gstpi expression analysis in zebrafish larvae after psychotropic agent exposure. RT-qPCR analysis was performed on total RNA from control and treated 3 dpf larvae after $24 \mathrm{~h}$ treatment with VPA (A), CBZ (B), LiCl (C), pentobarbital (D), caffeine (E) and theophylline (F). mRNA levels were determined using the zebrafish $\beta$-actin mRNA as internal standard and their expression relative to untreated controls was determined. Shown are the means \pm S.D. of one representative from three independent experiments. *** Statistical significance $P<0.005,{ }^{* *} P<0.01,{ }^{*} P<0.05$.

Matrix metalloprotease 13 ( $m m p 13$ ) is involved in inflammation and skeletal formation [53-55]. Its expression (Fig. 9) was found to be increased, following a dose dependant response for pentobarbital (from 4 to 23 -fold), caffeine ( 9 and 44 -fold) and theophylline (20 and 149 -fold). A significant mmp13 expression increase was also observed for VPA 135 and $155 \mu \mathrm{M}$ (10 and 5-fold) and $\mathrm{LiCl} 180 \mu \mathrm{M}$ (2-fold). Surprisingly, a 2.5 -fold decrease was induced by exposure to $\mathrm{CBZ} 44 \mu \mathrm{M}$ and $\mathrm{LiCl} 208 \mu \mathrm{M}$.
The $u c h l 1$ gene codes for an enzyme of the ubiquitin carboxyterminal hydrolase family involved in the control of ubiquitin metabolism, required for maintenance of a subset of functional neuronal axons and playing a role in protection against neurodegenerative diseases such as Parkinson or Alzheimer [56,57]. It was also shown to respond to oxidative stress [56]. The uchl1 gene was induced by treatments (Fig. 10) with VPA (up to 3-fold) and repressed for the three highest $\mathrm{CBZ}$ exposures (0.6-fold) and all 

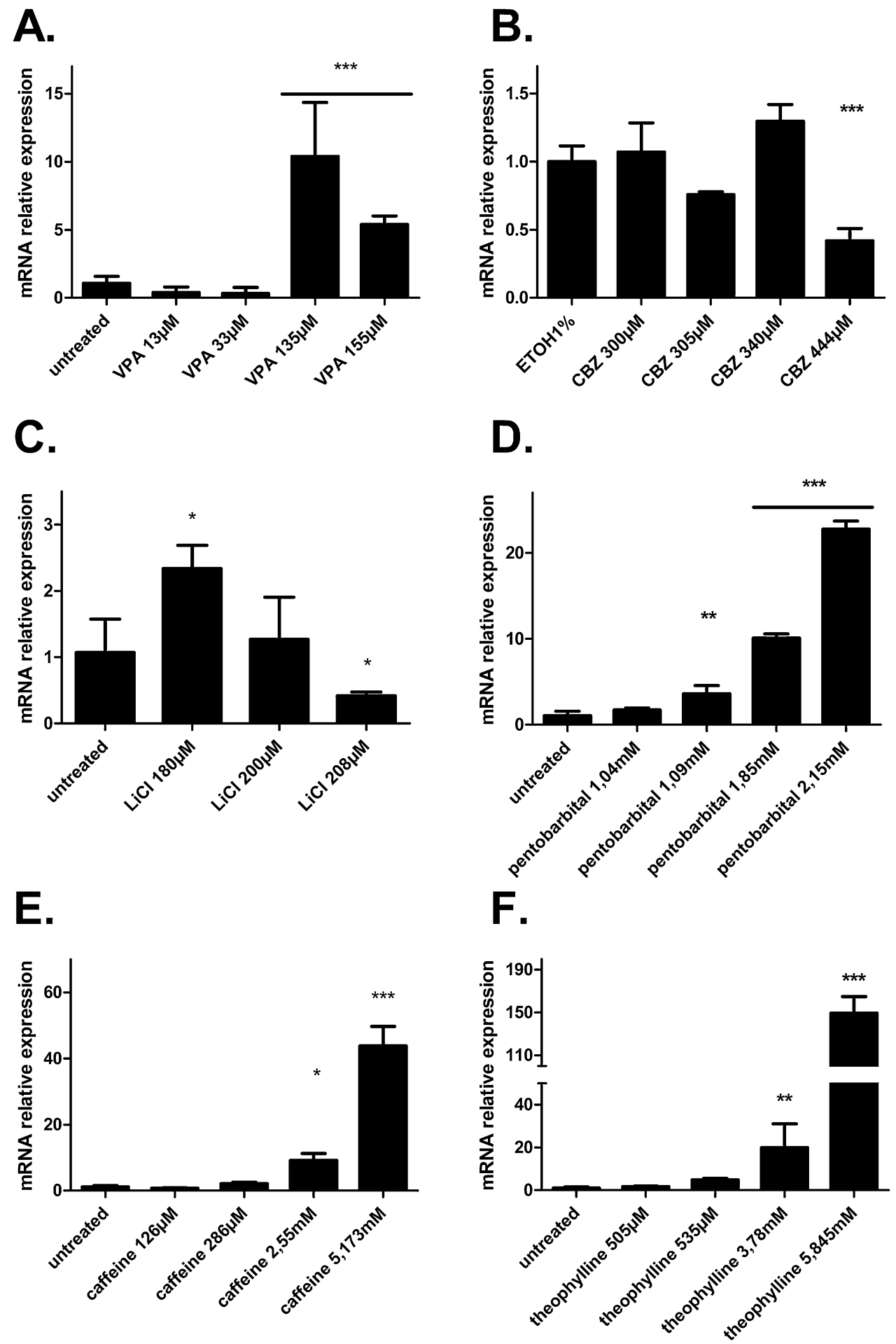

Fig. 9. $m m p 13$ expression analysis in zebrafish larvae after psychotropic agent exposure. RT-qPCR analysis was performed on total RNA from control and treated 3 dpf larvae after $24 \mathrm{~h}$ treatment with VPA (A), CBZ (B), $\mathrm{LiCl}(\mathrm{C})$, pentobarbital (D), caffeine (E) and theophylline (F). mRNA levels were determined using the zebrafish $\beta$-actin mRNA as internal standard and their expression relative to untreated controls was determined. Shown are the means \pm S.D. of one representative from three independent experiments. *** Statistical significance $P<0.005,{ }^{* *} P<0.01,{ }^{*} P<0.05$

pentobarbital exposure (from 0.25 to 0.5 -fold), while no significant effect was observed for caffeine and theophylline. A weak increase was also observed for $200 \mu \mathrm{M} \mathrm{LiCl}$ exposure (1.7-fold). Although it was shown that long-term lithium treatment can be beneficial in a transgenic mouse model for Alzheimers disease [58], the biological significance of our finding remains at present unclear.

When the transcriptional effects of the drugs are represented as a function of concentration for each of the four genes tested
(Fig. 11), different groups are apparent. VPA stands out by causing a weak induction of $u c h l 1$ and gstpi expression at all concentrations, but a biphasic effect on $h s p 70$ and $m m p 13$ gene expression; repression at low concentrations and induction at higher concentrations. CBZ significantly affected gene expression only at LC50 concentration, with an increase of $h s p 70$ and gstpi and a decrease of $u c h l 1$ and $m m p 13$ gene expression. LiCl caused an increase of $h s p 70$ gene expression at all tested concentrations, but an increase at 

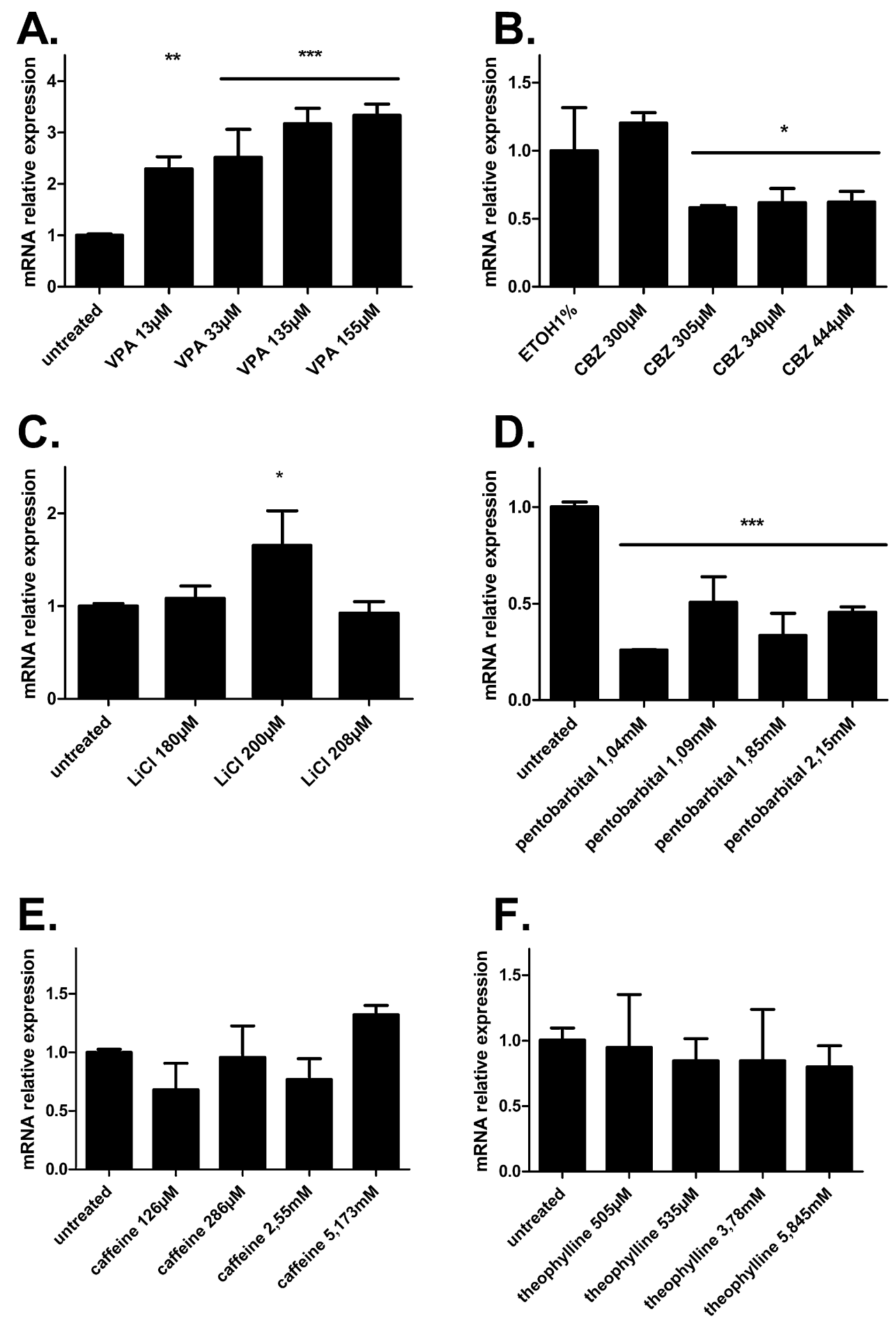

Fig. 10. uchl1 expression analysis in zebrafish larvae after psychotropic agent exposure. RT-qPCR analysis was performed on total RNA from control and treated 3 dpf larvae after $24 \mathrm{~h}$ treatment with VPA (A), CBZ (B), LiCl (C), pentobarbital (D), caffeine (E) and theophylline (F). mRNA levels were determined using the zebrafish $\beta$-actin mRNA as internal standard and their expression relative to untreated controls was determined. Shown are the means \pm S.D. of one representative from three independent experiments. ${ }^{* * *}$ Statistical significance $P<0.005,{ }^{* *} P<0.01,{ }^{*} P<0.05$.

Table 3

Lowest observed effect concentrations leading to a significant effect for heart rate, locomotion and gene expression analysis compared to EC10-48/72 and LC10-48/72.

\begin{tabular}{lllll}
\hline & Heart rate & Locomotion & Gene expression & EC10-48/72 \\
\hline VPA & $<50 \mu \mathrm{M}$ & $<50 \mu \mathrm{M}$ & $<13 \mu \mathrm{M}$ & $13 \mu \mathrm{M}$ \\
CBZ & $<350 \mu \mathrm{M}$ & $400 \mu \mathrm{M}$ & $<305 \mu \mathrm{M}$ & $305 \mu \mathrm{M}$ \\
LiCl & $<50 \mu \mathrm{M}$ & $150 \mu \mathrm{M}$ & $<180 \mu \mathrm{M}$ & $135 \mu \mathrm{M}$ \\
Pentobarbital & $1 \mathrm{mM}$ & - & $<1.04 \mathrm{mM}$ & $339 \mu \mathrm{M}$ \\
Caffeine & $3 \mathrm{mM}$ & $2 \mathrm{mM}$ & $<286 \mu \mathrm{M}$ & $1.041 \mathrm{mM}$ \\
Theophylline & $<5 \mathrm{mM}$ & $2 \mathrm{mM}$ & $<3.78 \mathrm{mM}$ & $126 \mu \mathrm{M}$ \\
\hline
\end{tabular}


A.

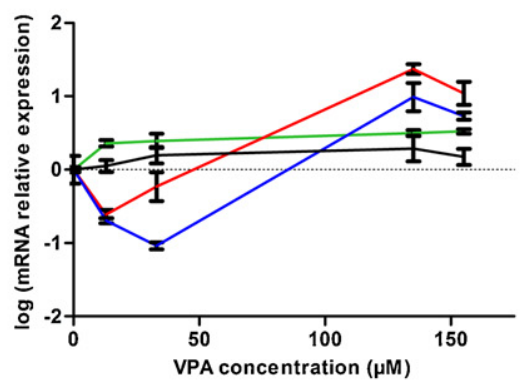

B.

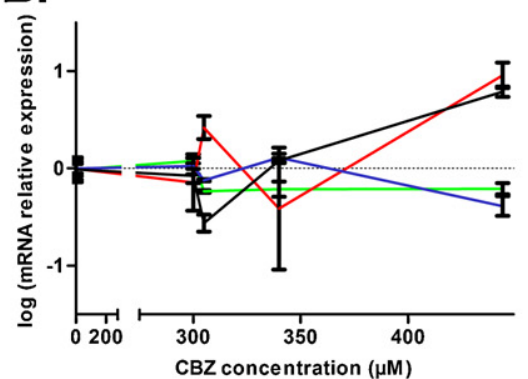

C.

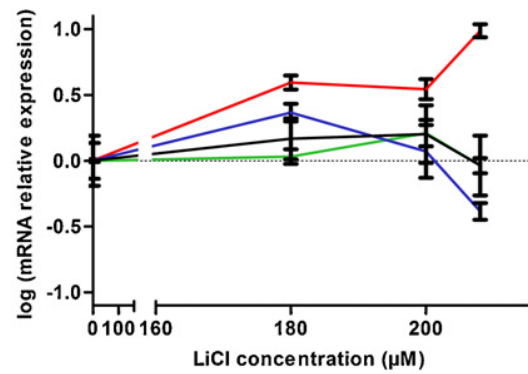

D.

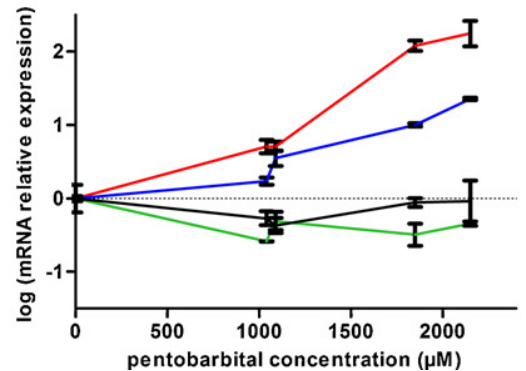

E.

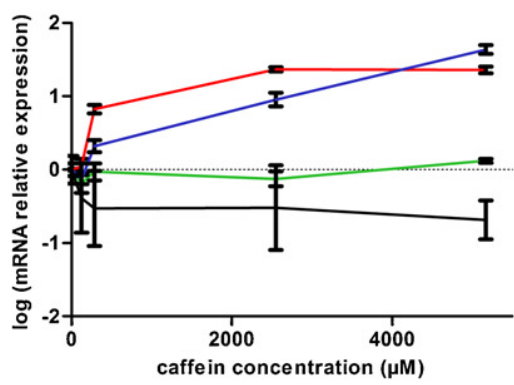

F.

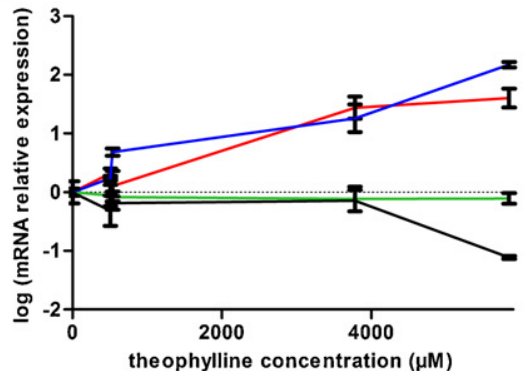

G.

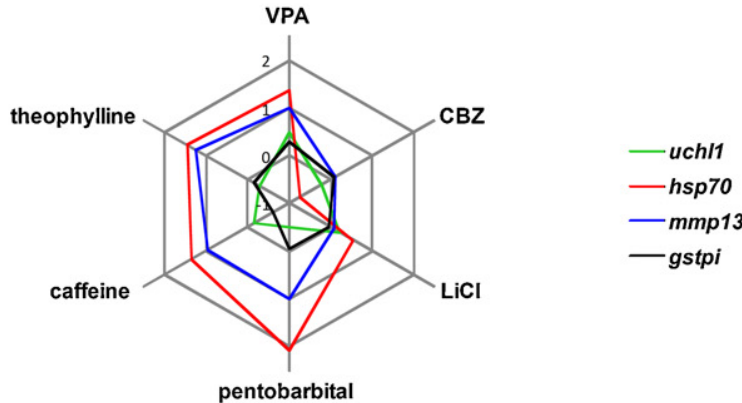

Fig. 11. Gene regulatory effects of psychotropic drugs. Dose dependant response of $u c h l 1$ (in green), $h s p 70$ (in red), $m m p 13$ (in blue) and gst-pi (in black) to VPA (A), CBZ (B), LiCl (C), pentobarbital (D), caffeine (E) and theophylline (F) at EC10 EC50 LC10 and LC50 concentrations, except for LiCl that was analyzed using LC10, LC50 and EC10. Fold-change relative to the corresponding untreated control is shown on a logarithmic scale. (G) Gene regulation profile for each drug at LC10 concentration on a radar graph, representing the four analyzed genes.

EC10 and a decrease at LC50 of mmp13 expression. Pentobarbital, caffeine and theophylline caused a dose-dependent increase of hsp70 and mmp13 that was already clearly apparent at EC10 concentrations, while only caffeine and theophylline caused a decreased gstpi expression at LC50 (or lower for caffeine). Conversely, on a radar plot representing the modulation of expression of the four genes by the different drugs at their respective LC10 concentration (Fig. 11G), a similarity of the hsp70 and mmp13 gene responses is clearly apparent. Only CBZ exerts opposite effects on these genes.
Taken together, our results indicate that gene expression studies on a few genes at $3 \mathrm{dpf}$ after $24 \mathrm{~h}$ treatment with various drugs reveal specific patterns of gene regulation that might provide a means to classify the toxic potential of various substances and, after further studies, to identify the toxic mechanisms involved.

\section{Conclusion}

Zebrafish larvae are increasingly used as a powerful tool to investigate the effects of pollutants on an entire living vertebrate. 
Here, we decided to compare various endpoints to detect deleterious biological effects of a limited number of compounds on zebrafish larvae. We limited our study on pharmaceutically active compounds ( $\mathrm{PhACs}$ ) that are increasingly found in wastewater and end up in the surface water system, thus becoming an important issue in pharmacology and ecology.

We chose to study the effects of the different compounds by exposure between $48 \mathrm{hpf}$ and $72 \mathrm{hpf}$, a critical period for organogenesis in the developing larva. Although the major events in embryo development (gastrulation, conversion-extension, epiboly, segmentation) are terminated at this stage, later events such as organogenesis and growth also require similar regulatory pathways. In addition, previous studies revealed that extension of exposure between 2 and $3 \mathrm{dpf}$ results in a better consistency with observations in adults [18]. It was therefore interesting to investigate the effects specifically during this period.

The results of our survival tests clearly show that VPA and $\mathrm{LiCl}$ are highly toxic (Cat $1<1 \mathrm{mg} / \mathrm{l}$ ) to zebrafish larvae during this period, while pentobarbital, caffeine and theophylline can be declared non toxic $(>100 \mathrm{mg} / \mathrm{ml})$ based on our tests. CBZ exhibits a category 3 $(10-100 \mathrm{mg} / \mathrm{ml})$ toxicity until $2 \mathrm{dpf}$ and appears to be non-toxic on older larvae.

Interestingly, comparison of lethal concentrations at later stages as performed here (LC50-48/72 or LC50-48/144) to those determined at early stages (LC50-4/24 and LC50-4/48, see Table 1 ) reveals that early developmental stages display a much lower sensitivity to most of the tested compounds ( 4 out of 6 ), clearly indicating that the late stages should be included in lethality tests for complete assessment of toxicity. Some of these observations possibly reflect the fact that the chorion is largely blocking uptake of the drugs during early stages, while hatching takes place during the $48-72 \mathrm{hpf}$ period. Thus, an important fraction of older larvae will be directly exposed to the compound at least during a part of this treatment period. The importance of this phenomenon could be assessed in the future by exposing dechorionated embryos to the drugs [59] and by assessing the amount of drug that was taken up by the embryos by analytical methods such as mass spectrometry. Using a different set of toxicants, tests assessing morphological effects revealed a higher sensitivity of younger developmental stages [50]. It is unclear at this point how such divergent observations might occur. Hydrophobicity of the compound cannot entirely explain the discrepancies, as both studies used water-soluble as well as ethanol or DMSO-soluble substances. Note that our study concentrates on pharmacodynamic drugs, which might introduce a bias toward molecules that are active in adults and thus more prone to exert their effects in older larvae tests. Taken together, our results stress the importance to include exposure beyond $48 \mathrm{hpf}$ to correctly assess the possibly deleterious properties of compounds.

We also analyzed the effects of exposure between 48 and $72 \mathrm{hpf}$ on morphology, heart rate, locomotor activity and gene expression. These results complement previous studies focusing on early developmental defects and they show that many toxic mechanisms are still active at later life stages. Our results show that morphological and physiological (heart rate) defects are readily observed at concentrations comparable to earlier life stage tests. Behavioral tests, as performed here at $6 \mathrm{dpf}$ and 3 days after drug withdrawal proved to be quite insensitive except for VPA. Clearly, such tests should be performed immediately after or during exposure for sensitive results. When comparing the lowest concentrations leading to a significant effect for each type of analysis (Table 3), gene expression analysis appears clearly as the most sensitive approach to detect biological activity of a compound. Additional genes might be tested in the future and reveal to be even more sensitive. In a high throughput perspective, survival tests or heart rate determination are much easier and cost-effective to perform. Heart rate is affected at concentrations close to or mostly lower than EC50. However, several drugs such as $\mathrm{LiCl}$ or VPA decreased heart rate at concentrations well below their LC50. The induced morphological defects might be causing this decrease (e.g. VPA $50 \mu \mathrm{M}$ ), while those induced by lowest concentrations of caffeine or theophylline will have no effect on heart beat. Thus, heart rate determination could serve as a simple predictor for lethality and for some morphological defects, while other abnormalities will require direct morphological examination to be detected.

Some of the PHaCs tested here are found in surface water at concentrations sufficient to induce significant lethality and developmental defects in hatching zebrafish larvae, such as CBZ at $307 \mu \mathrm{M}$ or caffeine at $1.6 \mathrm{mM}$ [19]. Further investigations will be required to fully assess the impact of this new type of pollution on the aquatic fauna and, possibly on humans.

\section{Acknowledgments}

This work was supported by the Walloon Region (FEDER.GIGA2 Bioindustry support), the European Interreg Program Alma-insilico and the Fonds National de la Recherche Scientifique (FNRS). M.M. is a Chercheur Qualifié du FNRS. We also want to thank Marie Winandy of the GIGA-R zebrafish facility for providing zebrafish eggs as well as the sequencing, imaging and transcriptomics facilities of the GIGA-R institution for their competent support.

\section{Appendix A. Supplementary data}

Supplementary data associated with this article can be found, in the online version, at http://dx.doi.org/10.1016/j.reprotox. 2012.07.010.

\section{References}

[1] Molina G, Vogt A, Bakan A, Dai W, Queiroz de Oliveira P, Znosko W, et al Zebrafish chemical screening reveals an inhibitor of Dusp6 that expands cardiac cell lineages. Nature Chemical Biology 2009;5:680.

[2] Brittijn SA, Duivesteijn SJ, Belmamoune M, Bertens LF, Bitter W, de Bruijn JD, et al. Zebrafish development and regeneration: new tools for biomedical research. International Journal of Developmental Biology 2009;53:835.

[3] Froehlicher M, Liedtke A, Groh KJ, Neuhauss SC, Segner H, Zebrafish Eggen RI. (Danio rerio) neuromast: promising biological endpoint linking developmental and toxicological studies. Aquatic Toxicology 2009;95:307.

[4] Irons TD, MacPhail RC, Hunter DL, Padilla S. Acute neuroactive drug exposures alter locomotor activity in larval zebrafish. Neurotoxicology and Teratology 2009;32:84.

[5] Pruvot B, Jacquel A, Droin N, Auberger P, Bouscary D, Tamburini J, et al. Leukemic cell xenograft in zebrafish embryo for investigating drug efficacy. Haematologica 2011;96:612.

[6] Langenau DM, Keefe MD, Storer NY, Guyon JR, Kutok JL, Le X, et al. Effects of RAS on the genesis of embryonal rhabdomyosarcoma. Genes and Development 2007;21:1382.

[7] Zhuravleva J, Solary E, Chluba J, Bastie JN, Delva L. A role for the transcription intermediary factor 2 in zebrafish myelopoiesis. Experimental Hematology 2008;36:559.

[8] Campbell WA, Yang H, Zetterberg H, Baulac S, Sears JA, Liu T, et al. Zebrafish lacking Alzheimer presenilin enhancer 2 (Pen-2) demonstrate excessive p53-dependent apoptosis and neuronal loss. Journal of Neurochemistry 2006;96:1423

[9] Xia W. Exploring Alzheimer's disease in zebrafish. Journal of Alzheimer's Disease 2010;20:981.

[10] Teraoka H, Dong W, Hiraga T. Zebrafish as a novel experimental model for developmental toxicology. Congenital Anomalies (Kyoto) 2003:43:123.

[11] Spitsbergen JM, Kent ML. The state of the art of the zebrafish model for toxicology and toxicologic pathology research - advantages and current limitations. Toxicologic Pathology 2003;31(Suppl.):62.

[12] Nagel R, Dar T. The embryo test with the zebrafish Danio rerio - a general model in ecotoxicology and toxicology. Altex-Alternativen $\mathrm{Zu}$ Tierexperimenten 2002;19:38.

[13] Embry MR, Belanger SE, Braunbeck TA, Galay-Burgos M, Halder M, Hinton DE, et al. The fish embryo toxicity test as an animal alternative method in hazard and risk assessment and scientific research. Aquatic Toxicology 2010;97:79.

[14] Halling-Sorensen B, Nors Nielsen S, Lanzky PF, Ingerslev F, Holten Lutzhoft HC, Jorgensen SE. Occurrence, fate and effects of pharmaceutical substances in the environment - a review. Chemosphere 1998;36:357. 
[15] Santos LH, Araujo AN, Fachini A, Pena A, Delerue-Matos C, Montenegro MC. Ecotoxicological aspects related to the presence of pharmaceuticals in the aquatic environment. Journal of Hazardous Materials 2010;175:45.

[16] Ferrari B, Paxeus N, Lo Giudice R, Pollio A, Garric J. Ecotoxicological impact of pharmaceuticals found in treated wastewaters: study of carbamazepine, clofibric acid, and diclofenac. Ecotoxicology and Environment Safety 2003;55:359.

[17] Gibs J, Stackelberg PE, Furlong ET, Meyer M, Zaugg SD, Lippincott RL. Persistence of pharmaceuticals and other organic compounds in chlorinated drinking water as a function of time. Science of the Total Environment 2007;373:240.

[18] Khetan SK, Collins TJ. Human pharmaceuticals in the aquatic environment: a challenge to green chemistry. Chemical Reviews 2007;107:2319.

[19] Mompelat S, Le Bot B, Thomas O. Occurrence and fate of pharmaceutical products and by-products, from resource to drinking water. Environment International 2009;35:803.

[20] Gould TD, Manji HK. The Wnt signaling pathway in bipolar disorder. Neuroscientist 2002;8:497.

[21] Feng HL, Leng Y, Ma CH, Zhang J, Ren M, Chuang DM. Combined lithium and valproate treatment delays disease onset, reduces neurological deficits and prolongs survival in an amyotrophic lateral sclerosis mouse model. Neuroscience 2008;155:567.

[22] Westerfield M. THE ZEBRAFISH BOOK, 5th edition: a guide for the laboratory use of zebrafish (Danio rerio). Eugene: University of Oregon Press; 2007.

[23] Kimmel CB, Ballard WW, Kimmel SR, Ullmann B, Schilling TF. Stages of embryonic development of the zebrafish. Developmental Dynamics 1995;203:253.

[24] Pfaffl MW. A new mathematical model for relative quantification in real-time RT-PCR. Nucleic Acids Research 2001;29:2002.

[25] Steel RGD, Torrie JH. Analysis of covariance. In: Principles and procedures of statistics: a biometrical approach. 3rd ed. New York: McGraw-Hill; 1996. p. 401. ISBN: 9780070610286.

[26] Li X, Jia S, Wang S, Wang Y, Meng A. Mta3-NuRD complex is a master regulator for initiation of primitive hematopoiesis in vertebrate embryos. Blood 2009; $114: 5464$

[27] Farooq M, Sulochana KN, Pan X, To J, Sheng D, Gong Z, et al. Histone deacetylase 3 (hdac3) is specifically required for liver development in zebrafish. Developmental Biology 2008;317:336.

[28] Gurvich N, Berman MG, Wittner BS, Gentleman RC, Klein PS, Green JB. Association of valproate-induced teratogenesis with histone deacetylase inhibition in vivo. FASEB Journal 2005:19:1166.

[29] Isenberg JS, Jia Y, Field L, Ridnour LA, Sparatore A, Del Soldato P, et al. Modulation of angiogenesis by dithiolethione-modified NSAIDs and valproic acid. British Journal of Pharmacology 2007;151:63.

[30] Selderslaghs IW, Van Rompay AR, De Coen W, Witters HE. Development of a screening assay to identify teratogenic and embryotoxic chemicals using the zebrafish embryo. Reproductive Toxicology 2009;28:308.

[31] van den Brandhof EJ, Montforts M. Fish embryo toxicity of carbamazepine, diclofenac and metoprolol. Ecotoxicology and Environment Safety 2010;73:1862.

[32] Nassef M, Matsumoto S, Seki M, Khalil F, Kang IJ, Shimasaki Y, et al. Acute effects of triclosan, diclofenac and carbamazepine on feeding performance of Japanese medaka fish (Oryzias latipes). Chemosphere 2010;80:1095.

[33] Berridge MJ, Downes CP, Hanley MR. Neural and developmental actions of lithium: a unifying hypothesis. Cell 1989;59:411.

[34] Maslanski JA, Leshko L, Busa WB. Lithium-sensitive production of inositol phosphates during amphibian embryonic mesoderm induction. Science 1992;256:243.

[35] Stachel SE, Grunwald DJ, Myers PZ. Lithium perturbation and goosecoid expression identify a dorsal specification pathway in the pregastrula zebrafish. Development 1993;117:1261.

[36] Rana N, Moond M, Marthi A, Bapatla S, Sarvepalli T, Chatti K, et al. Caffeine-induced effects on heart rate in zebrafish embryos and possible mechanisms of action: an effective system for experiments in chemical biology. Zebrafish 2010;7:69.

[37] Chen YH, Huang YH, Wen CC, Wang YH, Chen WL, Chen LC, et al. Movement disorder and neuromuscular change in zebrafish embryos after exposure to caffeine. Neurotoxicology and Teratology 2008;30:440.

[38] Kennedy MD, Galloway AV, Dickau LJ, Hudson MK. The cumulative effect of coffee and a mental stress task on heart rate, blood pressure, and mental alertness is similar in caffeine-naive and caffeine-habituated females. Nutrition Research 2008;28:609.

[39] McClaran SR, Wetter TJ. Low doses of caffeine reduce heart rate during submaximal cycle ergometry. Journal of the International Society of Sports Nutrition 2007;4:11.

[40] Bichler A, Swenson A, Harris MA. A combination of caffeine and taurine has no effect on short term memory but induces changes in heart rate and mean arterial blood pressure. Amino Acids 2006;31:471.

[41] Turley KR, Gerst JW. Effects of caffeine on physiological responses to exercise in young boys and girls. Medicine and Science in Sports and Exercise 2006; 38:520.

[42] Chakraborty C, Hsu CH, Wen ZH, Lin CS, Agoramoorthy G. Effect of caffeine, norfloxacin and nimesulide on heartbeat and VEGF expression of zebrafish larvae. Journal of Environment biology 2011:32:179.

[43] Egan RJ, Bergner CL, Hart PC, Cachat JM, Canavello PR, Elegante MF, et al. Understanding behavioral and physiological phenotypes of stress and anxiety in zebrafish. Behavioural Brain Research 2009;205:38.

[44] Wong K, Elegante M, Bartels B, Elkhayat S, Tien D, Roy S, et al. Analyzing habituation responses to novelty in zebrafish (Danio rerio). Behavioural Brain Research 2010;208:450.

[45] Zhdanova IV, Wang SY, Leclair OU, Danilova NP. Melatonin promotes sleep-like state in zebrafish. Brain Research 2001;903:263.

[46] Renier C, Faraco JH, Bourgin P, Motley T, Bonaventure P, Rosa F, et al. Genomic and functional conservation of sedative-hypnotic targets in the zebrafish. Pharmacogenetics and Genomics 2007;17:237.

[47] Rihel J, Prober DA, Arvanites A, Lam K, Zimmerman S, Jang S, et al. Zebrafish behavioral profiling links drugs to biological targets and rest/wake regulation. Science 2010;327:348.

[48] Selderslaghs IW, Hooyberghs J, De Coen W, Witters HE. Locomotor activity in zebrafish embryos: a new method to assess developmental neurotoxicity. Neurotoxicology and Teratology 2010;32:460.

[49] Scholz S, Fischer S, Gundel U, Kuster E, Luckenbach T, Voelker D. The zebrafish embryo model in environmental risk assessment - applications beyond acute toxicity testing. Environmental Science and Pollution Research International 2008;15:394.

[50] Yang L, Kemadjou JR, Zinsmeister C, Bauer M, Legradi J, Muller F, et al. Transcriptional profiling reveals barcode-like toxicogenomic responses in the zebrafish embryo. Genome Biology 2007;8:R227.

[51] Ankley GT, Bencic DC, Breen MS, Collette TW, Conolly RB, Denslow ND, et al. Endocrine disrupting chemicals in fish: developing exposure indicators and predictive models of effects based on mechanism of action. Aquatic Toxicology 2009;92:168.

[52] Rahman Q, Abidi P, Afaq F, Schiffmann D, Mossman BT, Kamp DW, et al. Glutathione redox system in oxidative lung injury. Critical Reviews in Toxicology 1999;29:543.

[53] Saito M, Sato K, Kunisaki N, Kimura S. Characterization of a rainbow trout matrix metalloproteinase capable of degrading type I collagen. European Journal of Biochemistry 2000;267:6943.

[54] Ortega N, Behonick D, Stickens D, Werb Z. How proteases regulate bone morphogenesis. Annals of the New York Academy of Sciences 2003; 995:109.

[55] Zhang Y, Bai XT, Zhu KY, Jin Y, Deng M, Le HY, et al. In vivo interstitial migration of primitive macrophages mediated by JNK-matrix metalloproteinase 13 signaling in response to acute injury. Journal of Immunology 2008; $181: 2155$.

[56] Setsuie R, Wada K. The functions of UCH-L1 and its relation to neurodegenerative diseases. Neurochemistry International 2007;51:105.

[57] Day IN, Thompson RJ. UCHL1 (PGP 9.5): neuronal biomarker and ubiquitin system protein. Progress in Neurobiology 2010;90:327.

[58] Zhang X, Heng X, Li T, Li L, Yang D, Du Y, et al. Long-term treatment with lithium alleviates memory deficits and reduces amyloid-beta production in an aged Alzheimer's disease transgenic mouse model. Journal of Alzheimer's Disease 2011;24:739.

[59] Henn K, Braunbeck T. Dechorionation as a tool to improve the fish embryo toxicity test (FET) with the zebrafish (Danio rerio). Comparative Biochemistry and Physiology Part C: Toxicology and Pharmacology 2011; 153:91. 